\title{
The University of Zimbabwe College of Health Sciences (UZ-CHS) BIRTH COHORT study: rationale, design and methods
}

Kerina Duri ${ }^{1 *}$ (D), Felicity Z. Gumbo ${ }^{2}$, Privilege T. Munjoma ${ }^{1}$, Precious Chandiwana ${ }^{3}, K^{\prime}$ Kudakwashe Mhandire ${ }^{4}$ Asaph Ziruma ${ }^{5}$, Andrew Macpherson ${ }^{6}$, Simbarashe Rusakaniko ${ }^{7}$, Exnevia Gomo3,8, Benjamin Misselwitz ${ }^{6 \dagger}$, Lovemore Ronald Mazengera ${ }^{1+}$ and the UZ-CHS Birth Cohort Team

\begin{abstract}
Background: Commencing lifelong antiretroviral therapy (ART) immediately following HIV diagnosis (Option B+), has greatly improved maternal-infant health. Thus, large and increasing numbers of HIV-infected women are on ART during pregnancy, a situation concurrently increasing numbers of HIV-exposed-uninfected (HEU) infants. Compared to their HIV-unexposed-uninfected (HUU) counterparts, HEU infants show higher rates of adverse birth outcomes, mortality, infectious/non-communicable diseases including impaired growth and neurocognitive development. There is an urgent need to understand the impact of HIV and early life ART exposures, immune-metabolic dysregulation, comorbidities and environmental confounders on adverse paediatric outcomes.
\end{abstract}

Methods: Six hundred (600) HIV-infected and 600 HIV-uninfected pregnant women $\geq 20$ weeks of gestation will be enrolled from four primary health centres in high density residential areas of Harare. Participants will be followed up as mother-infant-pairs at delivery, week(s) 1, 6, 10, 14, 24, 36, 48, 72 and 96 after birth. Clinical, socio-economic, nutritional and environmental data will be assessed for adverse birth outcomes, impaired growth, immune/ neurodevelopment, vertical transmission of HIV, hepatitis-B/C viruses, cytomegalovirus and syphilis. Maternal urine, stool, plasma, cord blood, amniotic fluid, placenta and milk including infant plasma, dried blood spot and stool will be collected at enrolment and follow-up visits. The composite primary endpoint is stillbirth and infant mortality within the first two years of life in HEU versus HUU infants. Maternal mortality in HIV-infected versus -uninfected women is another primary outcome. Secondary endpoints include a range of maternal and infant outcomes. Substudies will address maternal stress and malnutrition, maternal-infant latent tuberculosis, Helicobacter pylori infections, immune-metabolomic dysregulation including gut, breast milk and amniotic fluid dysbiosis.

(Continued on next page)

\footnotetext{
*Correspondence: kduri@medsch.uz.ac.zw; kerina.duri@gmail.com

†Benjamin Misselwitz and Lovemore Ronald Mazengera contributed equally to this work and share last authorship

'Department of Immunology, University of Zimbabwe College of Health Sciences (UZ-CHS), P.O. Box A178 Avondale, Harare, Zimbabwe

Full list of author information is available at the end of the article
}

C C The Author(s). 2020 Open Access This article is licensed under a Creative Commons Attribution 4.0 International License, which permits use, sharing, adaptation, distribution and reproduction in any medium or format, as long as you give appropriate credit to the original author(s) and the source, provide a link to the Creative Commons licence, and indicate if changes were made. The images or other third party material in this article are included in the article's Creative Commons licence, unless indicated otherwise in a credit line to the material. If material is not included in the article's Creative Commons licence and your intended use is not permitted by statutory regulation or exceeds the permitted use, you will need to obtain permission directly from the copyright holder. To view a copy of this licence, visit http://creativecommons.org/licenses/by/4.0/. The Creative Commons Public Domain Dedication waiver (http://creativecommons.org/publicdomain/zero/1.0/) applies to the data made available in this article, unless otherwise stated in a credit line to the data. 
(Continued from previous page)

Discussion: The University of Zimbabwe-College of Health-Sciences-Birth-Cohort study will provide a comprehensive assessment of risk factors and biomarkers for HEU infants' adverse outcomes. This will ultimately help developing strategies to mitigate effects of maternal HIV, early-life ART exposures and comorbidities on infants' mortality and morbidity.

Trial registration: ClinicalTrial.gov Identifier: NCT04087239. Registered 12 September 2019.

Keywords: Perinatal HIV/ART exposures, Breastfeeding, Maternal comorbidities, Immune-metabolic dysfunction, Microbiota dysbiosis, Adverse birth outcomes, Neonatal/infant/childhood adverse outcomes, Resource limited setting

\section{Background}

Zimbabwe, a land-locked country in Southern Africa, is enduring a generalised human immunodeficiency virus type 1 (HIV-1) epidemic since 1985 [1]. With a population of 16 million, 1.3 million people were living with HIV-1 in 2016, of these, 200,000 were children under the age of 15 [2]. Like any other sub Saharan African (SSA) country, Zimbabwe is confronted with concomitant epidemics of HIV-1, co-infections [3-11] and noncommunicable diseases (NCDs) such as cardiovascular diseases and metabolic syndromes [12-15]. Furthermore, SSA infants and their mothers are exposed to malnutrition [16] and poor access to clean water, sanitation and hygiene $[17,18]$.

The introduction of antiretroviral therapy (ART) in SSA has greatly improved maternal-infant health $(2 ; 19$; 20). In 2013, Zimbabwe adopted the Option B+ strategy of commencement of lifelong ART immediately following HIV diagnosis. With ART and even worse without treatment, HIV-1 exposure is associated with adverse birth outcomes and HIV-infected pregnant women have higher rates of stillbirths, preterm births and deliveries of low birth weight infants compared to their HIVuninfected counterparts [19-25].

ART has greatly improved the outcome of infants with HIV-1 exposure. Without treatment, 31\% of HIVinfected mothers transmitted the virus to their infants by 6 months of age and most infants progressed to acquired immunodeficiency syndrome (AIDS) rapidly, with only $50 \%$ surviving beyond the age of two [26]. ART has reduced mother to child transmission (MTCT) of HIV-1 to less than $1 \%$ in developed countries, and greatly improved infant survival [27]. In Zimbabwe, the Option B+ strategy decreased HIV-MTCT rate to $3.6 \%$ in 2014 [28].

In spite of these benefits, concerns have been raised on the growing numbers of HIV-1 exposed uninfected (HEU) infants not achieving comparable health outcomes relative to their HIV-1 unexposed uninfected (HUU) counterparts. HEU infants were more likely to experience growth failure [29-32] and had 1.5-fold higher rates of hospitalisations and 2-3.9-fold higher mortality rates, mostly due to infections [33-37].
Neurodevelopmental outcomes were also worse in HEU children [38], possibly due to exposures to other maternal infections during pregnancy $[39,40]$ including coinfection with cytomegalovirus (CMV) [41-44].

Antiretroviral drugs can accumulate in the amniotic fluid [45], possibly explaining some adverse outcomes on foetal [46-48] and infant development [49-52]. Dolutegravir is slowly being introduced into clinical practice in SSA. However, it has been associated with a high risk of preterm delivery $(31.6 \%)$ and birth defects [53, 54].

HEU infants show aberrations of the immune system at birth [55-57] with systemic immune activation [56, 58] which could be linked to adverse health outcomes $[59,60]$. HEU infants also have lower antibody titres following vaccination $[61,62]$ with abnormal $\mathrm{B}$ - and $\mathrm{T}$ lymphocyte phenotypic profiles $[63,64]$. It is therefore unclear, whether HEU infants are able to mount protective lifelong responses to all vaccines promoted via the national Expanded Program of Immunization (EPI, Table 1).

Taken together, the health of the large and ever growing population of HEU infants is a great public health concern in SSA. There is a complex interplay of maternal-infant HIV and coinfections, ART exposures, immune dysregulation, NCDs and low sociodemographic status associated with food insecurity and poor sanitation. While individual risk factors have been

Table 1 The extended program of vaccination (EPI)

\begin{tabular}{ll}
\hline Age & Vaccine \\
\hline At Birth & BCG, (hepatitis b to be introduced soon) \\
6 weeks & Pentavalent 1, OPV1, pneumococcal 1, rotavirus 1, \\
10 weeks & Pentavalent 2, OPV2, pneumococcal 2, rotavirus 2, \\
14 weeks & Pentavalent 3, OPV3, IPV, pneumococcal 3, \\
9 months & Measles and rubella, \\
18 months & DTP, OPV booster, measles and rubella.
\end{tabular}

EPI was established by the WHO in 1974 to develop and expand immunization throughout the world. The Zimbabwe vaccination schedule is indicated. In addition, Vitamin A supplementation is given from 6 months of age and thereafter every 6 months until 5 years. Pentavalent: Diphtheria, Pertussis, Tetanus, Hepatitis B and Haemophilus influenzae type B. IPV inactivated poliovirus vaccine, OPV Oral polio vaccine, DTP Diphtheria, BCG Bacillus Calmette-Guérin 
well characterized, there is a need to analyse these parameters in a large comprehensive prospective analysis combining deep clinical, socio-demographic and environmental assessment with extensive bio-sampling, improving the detection of adverse health outcomes. In Zimbabwe, HEU infants have been well-studied during the pre-ART and monotherapy eras [37, 65]. However, contemporary evidence is lacking. We hereby introduce the University of Zimbabwe College of Health Sciences (UZ-CHS) Birth Cohort Study, aiming to address these challenges.

\section{Methods}

\section{Aim of the study}

This study aims to identify predictors for short- and long-term adverse infant outcomes in a resource limited setting. We will examine the impact of maternal HIV infection and comorbidities, cumulative ART exposure in utero and throughout the breastfeeding period, including the effects of maternal immune suppression, immune activation and environmental variables.

Our study is focusing on mortality and morbidity of HEU infants, testing established risk factors from previous cohorts done during the pre-ART and monotherapy eras. Data and biomaterials will be collected prospectively from mothers and infants from enrolment at $\geq 20$ weeks of gestation to 2 years after birth to enable capturing of infant development.

\section{Objectives and outcomes}

Primary outcomes:

- The primary outcome of this study is the frequency of stillbirth as well as perinatal and postnatal mortality until two years of age of HEU infants versus HUU infants in a multivariable analysis controlled for confounders.

- Maternal mortality from enrolment until two years after delivery in HIV-infected versus HIV-uninfected participants in a multivariable analysis controlled for confounders.

Secondary outcomes of our study include a range of maternal, birth and infant outcomes summarized in Table 2.

\section{Study setting}

The University of Zimbabwe College of Health Sciences (UZ-CHS) Birth Cohort study is a prospective observational cohort study comparing infants born to HIVinfected and HIV-uninfected women in a resource limited setting of Western high-density suburbs of Harare attending Municipal primary health polyclinics. One thousand two hundred (1200) pregnant women (600
HIV-infected mothers and 600 HIV-uninfected controls) at $\geq 20$ weeks of gestation will be enrolled from February 2016 to June 2019. Participants will be followed as mother-baby pairs (MIPs) at birth, within 10 days of life and at 6,10,14, 24, 48, 72 and 96 weeks of age.

Questionnaires will be administered and bio-samples for laboratory tests will also be acquired at each visit. Biomaterials will be acquired for specific tests including tests for infections, clinical biochemistry, full blood counts and immune status, dysbiosis (Tables 3). In addition, at each study visit maternal-infant clinical examinations will be done and used to assess health status including the impact of household and environmental factors. The study will be a non-interventional cohort study design, but participants will be offered health care and health education.

\section{Study sites, local municipal engagement and routine clinical care}

The Municipality of Harare has established 12 polyclinics each comprising units for primary health care, maternity, post-natal care and a family health service. Medical services include HIV counselling and rapid testing including initiation and administration of ART. Monitoring and follow-up for other chronic conditions including diabetes mellitus and arterial hypertension are also offered. A physician comes twice a week per site to attend to complicated cases. Maternity services comprise antenatal care, postnatal care, treatment of hypertensive disorders, HIV and syphilis screening and treatment.

For each pregnant woman, routine lab results and management prior to enrolment into the study are well documented in antenatal booklets during routine clinical care. The study team will have access to these clinical data during and after the enrolment visit. The standard of care for all Zimbabwean HIV-infected women to prevent HIV-MTCT consists of (non)-nucleoside reverse transcriptase inhibitors; TENOLAM-E (Tenofovir, Lamivudine and Efavirenz, and to breastfeed as long as they choose to. Exclusive breast-feeding is encouraged during the first six months of life, with breastfeeding along with appropriate complementary foods up to 2 years of age or even older. According to Zimbabwean national guidelines, all HIV-infected women should be on Option B+, but in practice women often do not receive a timely HIV diagnosis.

Independent from our study, all infants including HIV-1 exposed and infected (HEI) infants, are monitored for growth, and also receive vaccination as shown in Table 1 as per the Zimbabwean EPI program. Clinic visits for any ailments are managed at a local primary health centre with complicated cases being appropriately referred to the nearest tertiary hospital. All HIV exposed infants are tested for HIV by reverse transcriptase 
Table 2 Secondary outcomes of UZ-CHS Birth cohort study

\section{Secondary outcomes}

1. Comparison of morbidity of HEU vs. HUU infants, defined as impaired growth, immune- and neuro-development and/ or frequent of clinically relevant infections.

2. To determine any association of ART exposure in utero and during breast feeding with pregnancy outcome, infant (HUU, HEU, HEI) growth and immune- and neuro-development.

3. To determine vertical transmission rates for HIV at birth and within the first 2 years of life and assess risk factors for transmission.

4. To determine the association between maternal baseline and delivery ART levels in different compartments and infant HIV infection, mortality and morbidity.

5. To determine HIV drug resistance profiles in mother and infants unresponsive to ART.

6. To assess abnormalities including lipid profiles, bone, haematological and hepatic toxicities associated with exposure to ART among mothers and infants.

7. To determine antenatal co-infections including HBV, HCV, CMV, syphilis, intestinal helminths and parasites as single infection or combined infections in HIV-infected and HIV -uninfected - women and determine the impact on pregnancy outcome, infant mortality and morbidity.

8. To determine the prevalence of infant infectious comorbidities; HBV, HCV, CMV, syphilis, including time points of infections and impact on mortality and morbidity.

9. To determine the prevalence of maternal NCDs (malnutrition/ obesity, anaemia, diabetes, hypertensive disorders) and determine their impact on pregnancy outcomes, infant mortality and morbidity.

10. To determine infant non-infectious comorbidities (e.g. anaemia, atopic dermatitis, congenital infections and other conditions) and their impact on mortality and morbidity.

11. To determine maternal household non-biological factors (socioeconomic state, hygiene) and determine their impact on pregnancy outcome, infant mortality and morbidity.

12. To determine antenatal reference ranges for MUAC, haemoglobin from FBC analyses, and biochemistry (kidney function, liver function tests, bone, lipid profiles) in pregnant women with a favourable outcome of pregnancy.

13. To assess delayed neurological development using the Denver II tool in HUU, HEU and HEl infants from 6 weeks to 2 years of age.

14. To determine humoural immune responses to EPI vaccines (e.g. antibody levels against measles, tetanus, diphtheria, pertussis, polio and rotavirus) in HUU, HEU and HEl infants.

15. To determine maternal intestinal parasites load using $18 \mathrm{~S}$ sequencing in pregnancy and relate it to infant immune development and atopy (antiinflammatory (IL-4, - 5, - 13) and regulatory cytokines (IL-10, TGF- $\beta$ ) at delivery, 6 weeks 48 and 96 weeks of age.

16. To determine immune activation and systemic inflammatory biomarkers in HUU, HEU and HEI infants at delivery, 6, 48 and 96 weeks of age.

17. To determine biomarkers for endothelial dysfunction including microbial translocation in HUU, HEU and HEl infants at delivery, 6, 48 and 96 weeks of age.

18. To determine host genetic markers for infectious disease susceptibility including HLA and KIR gene variants and their association with infection rates of HIV and co-infections in mothers and their infants.

19. To characterize pathogen genetic diversity including HIV, HBV, HCV, CMV subtypes, prevalent in our study population at time of infection/ earliest available samples and/or at 2 years.

$A R T$ antiretroviral therapy, CMV cytomegalovirus, FBC full blood count, $H B V$ hepatitis $B$ virus, $H C V$ hepatitis $C$ virus, $H L A$ human leukocyte antigen, $H I V$ human immune deficiency virus, HEI HIV exposed and infected, HEU HIV exposed but uninfected, HUU: HIV unexposed and uninfected, IL interleukin, KIR killer immunoglobulin like receptor, MUAC mid upper arm circumference, NCD non-communicable diseases, TGF transforming growth factor

polymerase chain reaction (RT-PCR) (Table 3, point ii.) at birth, 6 weeks of age and after cessation of breast feeding. Upon detection of HIV infection, infants are immediately commenced on ART, usually comprising the protease inhibitors Lopinavir/ritonavir and the nucleoside reverse transcriptase inhibitors; Zidovudine and Lamivudine. In addition, all HIV exposed infants are commenced on Cotrimoxazole prophylaxis until they stop breast feeding or they test HIV RT-PCR positive, whichever occurs first.

It costs a pregnant woman United States (US) twenty-five dollars $(\$ 25)$ to access antenatal services until six weeks after delivery whilst health care services are free of charge for infants until 5 years of age. They are encouraged to book early during pregnancy (at week 4-12 gestational age) and to test for HIV together with their spouses/partners. Currently, due to social-economic challenges, most Zimbabwean pregnant women go for antenatal registration at the polyclinics when their pregnancies are at advanced stages, a situation that puts their unborn babies at risk for HIV transmission, perpetuating the vicious cycle of poverty and HIV infections.

Following a pre-study site feasibility assessment in September 2015, out of the 12 polyclinics, Kuwadzana, Dzivaresekwa (Rujeko), Glenview and Budiriro in South West of Harare city centre were selected based on the higher volumes of maternal and child health services, frequency of HIV positivity and lack of competing research activities targeting the same 
Table 3 Summary of the tests done in mothers and infants at different time points

\begin{tabular}{|c|c|}
\hline Assessments & Method/threshold value(s) \\
\hline $\begin{array}{l}\text { HIV-1/2 diagnosis: } \\
\text { All HIV uninfected women at enrolment and every } \\
6 \text { months. } \\
\text { All HIV exposed infants from } 18 \text { months of age }\end{array}$ & $\begin{array}{l}\text { Qualitative rapid immunochromatographic, whole } \\
\text { blood serial testing algorithm according to the } \\
\text { national guidelines for HIV testing and counselling } \\
\text { [66]. }\end{array}$ \\
\hline
\end{tabular}

\section{Early infant HIV diagnosis}

HIV-1 RNA Qualitative Test on dried blood spots

All HIV exposed infants from delivery, at every visit until weaning or diagnosis of HIV infection up to 18 months of age [67].

\section{HIV-1 RNA quantification:}

In plasma, of all HIV infected women at enrolment and exit

In BM colostrum, and every 6 months

All HIV infected infants' earliest positive DBS

sample and at exit

\section{Immune status assessment:}

All HIV infected women at enrolment and exit All HIV infected infants earliest positive whole blood sample and at exit

\section{Maternal ART levels:}

Efavirenz, Lamivudine, Tenofovir will be tested enrolment, and every 12 months in all mothers on ART

\section{Syphilis serology:}

All mothers at enrolment and exit

All exposed infants from delivery and at every visit $\mathrm{HBV} / \mathrm{HCV}$ serology:

All mothers at enrolment and exit

All exposed infants from delivery and at every visit (DBS)

\section{HBV DNA Assays:}

Host genetics of HBV infection susceptibility

CMV serology:

All mothers at enrolment and exit

CMV DNA test:

All mothers at enrolment and exit

All exposed infants from delivery and at every visit (DBS)

Host genetics of CMV infection/ transmission

\section{Clinical biochemistry}

All mothers serum at enrolment and exit All infants serum within, 6 and 24 months of age

\section{Full blood counts:}

All mothers at enrolment and exit

All infants within 10 days of life, 6 and 24 months of age

Maternal blood random glucose and HbA1c: Once in pregnancy at enrolment

\section{Intestinal pathogens:}

All mothers at enrolment and exit All Infants at exit

Humoural immune responses to EPI vaccines Infants At 6 weeks, 12 and 24 months of age The lower detection limit of the assay; 20 copies/ $\mathrm{mL}$ blood sample CD4 ${ }^{+}$T-lymphocyte (percentage) and amniotic-fluid as previously described [68]

Detection of anti-Treponema pallidum antibodies in serum.

HBsAg detection,

Profiling; HBsAg, HBsAb, HBeAg, HBeAb \& HBcAb

DNA for occult hepatitis determination

HBV plasma DNA levels

HLA, KIR typing (whole blood)

CMV IgG, IgM levels, avidity assays. urine

CMV DNA in DBS

HLA, KIR typing albumin eGFR [70]

Liver enzymes

Including AST, GGT, bilirubin, LDH, ALP Cardiac markers; troponin CKMB. Lipids; total and LDL/HDL cholesterol. Bone profile; calcium, magnesium, phosphate.

Maternal haemoglobin concentration $<11.0 \mathrm{~g} / \mathrm{dl}$ and, and varying with age for infants, $<13.5 \mathrm{~g} / \mathrm{dl}$ ) weeks of age [72].

Cut off values for random glucose of $110 \mathrm{mg} / \mathrm{dl}$ mellitus whilst an $\mathrm{HbA} 1 \mathrm{c} \geq 5.6 \%$ will mark [73]. for, $\mathrm{H}$ pylori, intestinal protozoa and helminths trophozoites and ova.

Antibody titres EPI will be measured $[74,75]$.

\section{Equipment/ kits/comment}

Initial screening; SD Bioline HIV-1/2 3.0 (Standard

Diagnostics Inc., Kyonggi-do, South Korea.

-Confirmation; Alere Determine ${ }^{\mathrm{TM}}$ HIV-1/2 (Abbott

-Diagnostics, Lake Bluff, USA).

-Tie breaker; Western blotting, The Orasure kit, Epitope Inc., USA

COBAS1 AmpliPrep/ COBAS1 TaqMan1 HIV-1 RNA Qualitative Test (Roche Molecular System Inc., Branchburg, NJ, USA.

According to the manufacturer's recommendations.

Automated TaqMan Roche Amplicor 1.5 Monitor Test (Cobas AmpliPrep/Cobas TaqMan, Roche Diagnostics, Branchburg NJ, USA.

CD4 ${ }^{+}$T-lymphocyte (absolute) count EDTA whole

Different compartments, plasma, breast milk, urine and a non-Treponemal slide agglutination test for the semi-quantitative detection of plasma reagins

Plasma, breast milk HBV

CMV DNA in plasma, amniotic fluid breast milk and

Renal; creatinine, urea, uric acid, Urinary protein and within the first month of life and $<10.7 \mathrm{~g} / \mathrm{dl}$ from 9 $(6.1 \mathrm{mmol} / \mathrm{L})$ within $2 \mathrm{~h}$ of a meal or $101 \mathrm{mg} / \mathrm{dl}(5.6$ $\mathrm{mmol} / \mathrm{L}$ ) more than $2 \mathrm{~h}$ postprandial. A cut off for $\mathrm{HbA} 1 \mathrm{c}$ of $6.5 \%$ will identify undiagnosed diabetes individuals with an increased risk for future diabetes

Maternal and infant stool samples will be screened
Partec Cyflow counter (Munster, Germany) be performed within $6 \mathrm{~h}$ of whole blood collection.

Agilent Technologies, Palo Alto High performance liquid chromatography, Agilent 6430 Triple Quadrupole LC-MS/MS system, CA, USA.

Qualitative rapid immunochromatographic and, SD Bioline 3.0, SD Biosensor, Korea

Fortress diagnostics Ltd., UK

Screening; SD Bioline, Korea

Confirmation: Quality kit, USA

Tie breaker: Acon, USA

HBV profile All positives: 5 profile (CTK, USA)

HBV TaqMan PCR Kit, Norgen Biotek, Norway COBAS1 AmpliPrep/ COBAS1 TaqMan1 HBV DNA

Quantitative Test (Roche Molecular System Inc., Branchburg, NJ, USA

As previously described (112).

PerkinElmer kits, Euroimmun, South Africa

RealStar CMV PCR kit v1.0 (Altona Diagnostics,

Hamburg, Germany), following isolation of viral

DNA using the QIAamp MinElute Virus Spin Kit

As previously described [69].

Beckman Coulter AU680 chemistry analyser (Krefeld Germany)

Urinalysis strips, Cypress Diagnostics. HELLP syndrome for acute kidney injury assessment $\mathrm{LDH}$ : AST ratio > 22 distinguishing TTP from HELLP syndrome. Keiser SD [71]. All results to determine antenatal reference ranges associated favourable outcome of pregnancy

Mindray@ Haematology 3-part differential, 16 parameters BC3600 Analyser (Shenzhen, China) Determine antenatal reference ranges associated favourable outcome of pregnancy

Mindray BS200 Chemistry Analyser (Mindray, Shenzen, China)

Determine antenatal reference ranges associated favourable outcome of pregnancy

Direct wet mount microscopy and the formal-ether concentration technique [124].

The Bio-Plex ${ }^{\circledast} \mathbf{2 0 0}$ system Luminex analyser, BioRad, CA, USA
(Qiagen, Hilden, Germany). 
Table 3 Summary of the tests done in mothers and infants at different time points (Continued)

Assessments
Plasma inflammation and cell stress
biomarkers:
In a subgroup of MIPS with different durations of
exposures to ART from pregnancy to 12 months of
age

\section{Plasma metabolomics:}

> 400 analytes, in a subgroup of MIPs with different durations of exposures to ART from pregnancy to 12 months of age to assess altered amino acid and lipid metabolism

Infants atopic sensitization

Infant blood samples from 6, 24 and 96 weeks.

Breast milk characterisation

Maternal milk from delivery up to weaning time

\section{Lab based Sub studies assessments}

Plasma inflammatory biomarkers In a subgroup of MIPs from pregnancy, breastfeeding period and after weaning

Multiplexed 165 sequencing

In a subgroup of MIPs from pregnancy,

breastfeeding period and after weaning

Breast milk (whole) immune-metabolomics In MIPs with adverse outcomes, from colostrum, and at least 3 later points.

Maternal mycotoxins biomarkers

In pregnancy, at delivery and exit

Natural killer (NK) cells characterisations In a subgroup of HEU (with short, medium and long term ART exposures) versus HUU infants two time points between 12 and 24 months of age.

Maternal latent TB testing:

In a subgroup of HIV infected and uninfected in pregnant women and 6 weeks postpartum

Salivary cortisol levels

In a subgroup of MIP at 6 months follow up visit

\section{Helicobacter pylori testing}

In a subgroup of MIP from pregnancy to exit

Method/threshold value(s)

At least 25 inflammatory chemokines and cytokines measurements.

\section{Equipment/ kits/comment}

The Bio-Plex ${ }^{\circledast} \mathbf{2 0 0}$ system Luminex analyser, Bio-

Rad, CA USA

UPLC; TQMS; QTOF -HPLC; UHPLC -; MS/MS - Triple Quadrupole Mass Spectrometer.

\section{3 platforms}

-Biogenic amines (Amino acids, catecholamines \& polyamines), Signalling lipids (Sphingosine-1-

phosphate etc., Positive lipids (Lysophospholipids, phospholipids, cholesterol esters, di/triglycerides \& sphingomyelins) as described [76].

Total and specific serum IgE against food/aeroallergens will be assessed in selected Infants with specific serum lgE levels $>0.3 \mathrm{IU} / \mathrm{mL}$ will be considered sensitised $[77,78]$.

Micro-/macronutrients, vitamins, oligosaccharides, immunological biomarkers, essential fatty PUFAs such aslinoleic acid and a-linolenic acid: precursors of LCPUFA e.g. arachidonic acid and docosohexaanoic acid, from birth until weaning [79].

-7 panels, including cytokines, chemokines, vascular injury, angiogenesis, Th17.

$16 \mathrm{~S}$ rRNA gene segment spanning $\mathrm{V} 5$ and $\mathrm{V} 6$ regions in stool, plasma and breast milk as previously described [80].

Non-targeted injection analysis.

Level of mycotoxin biomarkers including aflatoxins $\mathrm{B} 1$ and 2 in urine, amniotic-fluid and milk

NK cells surface marker staining: CD2, CD3, CD16, CD56, CD69, KIR and mitochondria functional assays following PBMC isolation, including nutrient transporter expression on NK cells: Glut1, CD98, and CD71. Mitochondrial function of NK cells will be done using mitotracker green and mitotracker deep red assays

CD4/CD8 IGRAs against TB antigens (ESAT-6/CFP10/TB-7.7 against TST/ Mantoux at $0.1 \mathrm{ml}$ dose.

Test done according to the manufacturer's recommendations. Sensitivity is $0.007 \mu \mathrm{g} / \mathrm{dl}$.

Quantitative ELISA; H. pylori lgG IgA, IgM antibodies and detection of $\mathrm{H}$ pylori antigens from birth to 24 months according to the manufacturer's recommendations $\mathrm{H}$ pylori Ag Sensitivity:0.165 ng/ $\mathrm{ml}$.
Immuno-assay analyser (Thermofisher, Freiburg, Germany).

Gas chromatography, GC-CP3800, Varian, USA) equipped with a flame ionization detector and a fused silica capillary column $50 \mathrm{~m} \times 0.25 \mathrm{~mm}$ (I.D. CP-SIL 88 for FAME), Pennsylvania (PA) 16,823-0048, USA).

V-PLEX Human Biomarker 54-Plex Kit, ECL Technology, Maryland, USA

Illumina MiSeq/lon Torrent PGM sequencer.

Mass spectrometry (TQF-MS), Agilent 6550, Agilent Technologies Inc., Santa Clara, CA.

Measurement will be performed on Agilent 6430 USA

The BD LSR Fortessa ${ }^{\mathrm{TM}}$ cell analyser, multicolour (16 colour) flow cytometer assays, BD Sciences

Qiagen QuantiFERON gold plus kit, USA, Tuberculin purified protein derivative (PPD) Mantoux, Tubersol $^{R}$, Sanofi Pasteur, in tween solution, 5 US units per test

Salimetrics, LLC competitive enzyme immunoassay kit, Carlsbad, CA USA. ELISA, Monobind Lake Forest, CA USA. Triple Quadrupole LC-MS/MS system, Palo Alto, CA,

Sandwich enzyme Immunoassay, Colorimetric test

\footnotetext{
$A L P$ alkaline phosphatase, $A S T$ aspartate aminotransferase, $B M$ breast milk, $C D$ cluster of differentiation, $C K-M B$ creatine kinase-myocardial band, $C M V$ cytomegalovirus, EPI expanded program for immunization, GC gas chromatography, GGT gamma-glutamyl transferase; Glut1 glucose transporter-1, $H b A 1 c$ glycosylated haemoglobulin, $H B C A b$ hepatitis $B$ core antibody, $H B e A b$ hepatitis $B$ e-antibody, $H B e A g$ hepatitis $B$ e-antigen, $H B s A b$ hepatitis $B$ surface antibody, HBsAg hepatitis B surface antigen, $H B V$ hepatitis B virus, $H C V$ hepatitis $C$ virus, $H D L$ high density lipoprotein, $H E I$ HIV exposed infected, HELLP haemolysis, elevated liver enzymes and low platelet count, HEU HIV exposed but uninfected, HIB Haemophilus influenza type b, HIV human immunodeficiency virus, HLA human leukocyte antigen, HPLC high-pressure liquid-chromatography, HUU HIV unexposed and uninfected, IGRAs interferon gamma release assays, KIR killer cell immunoglobulin-like receptor, LCPUFA long chain poly unsaturated fatty acids, $L D H$ lactate dehydrogenase, LDL low density lipoprotein, MIPs mother-infant pairs, MS mass spectrometer, PUFA poly unsaturated fatty acids, QToF quad time of flight, TB tuberculosis, TQMS triple quadrupole mass spectrometer, TST tuberculin skin test, TTP thrombotic thrombocytopenic purpura, UHPLC ultrahigh-pressure liquid-chromatography, UPLC ultra-pressure liquid-chromatography
} 
population. The catchment areas of the selected four polyclinics have relatively stable communities that do not frequently change their rented accommodation. For this study, Municipal midwives at the selected facilities will assist with sample/data collection for deliveries that will occur late at night.

\section{Background characteristics of study participants}

All participants reside in South-Western high-density areas of Harare. Residents of this community are of relatively poor socio-economic status with high unemployment rates. Most households generally cannot afford 3 decent meals per day. Most families (72\%) live on less than 1 dollar per day [81] and supplement their diet through small scale vegetable gardening around their houses. Families live in houses of similar structure and size $\left(200 \mathrm{~m}^{2}\right)$. On average 2-6 families live in these relatively small houses and in some extreme situations up to 5 family members share a single room. Water supply is erratic, necessitating the use of communal boreholes at 200-1500 metres distance. This manually fetched water is used for drinking, cooking, bathing and flushing of toilets. Sewage bursts are common and may occur close to these boreholes. Contaminated boreholes in two of our four study sites, Budiriro and Glenview, have been epicentres of the 2018 cholera epidemics [7]. Residents of these high-density residential areas share a disproportionate burden of infectious diseases relative to those living in low-density areas in the same city.

\section{Study participants}

UZ-CHS birth cohort study enrolled consenting pregnant women registering for antenatal care at any of the 4 selected City of Harare polyclinics. Upon delivery, babies will be automatically recruited into the study and followed up as MIPs for two years. In cases of multiple births (twins or triplets) all infants of the recruited mother will be followed. Follow up is feasible and relatively easy in Zimbabwe where about $90 \%$ of pregnant women own or have access to a mobile phone [82].

\section{Inclusion and exclusion criteria}

Pregnant woman of Bantu origin should be $\geq 15$ years of age, at least 20 weeks of gestation at enrolment and planning to deliver at any of the 4 study sites. Due to the current economic challenges, nearly all pregnant women in high-density areas in Harare present to Municipal health clinics at or beyond 20 weeks of pregnancy. Therefore, no upper limit for gestational age for inclusion applies, to ensure a representative study population. All pregnant women with a documented positive HIV status will be encouraged to enrol in the study. For every HIV-infected pregnant woman recruited, the 10th HIVuninfected woman presenting to the same primary health clinic for the initial antenatal registration will be recruited, accounting for the $12 \%$ HIV prevalence within this population. The pregnancy will be dated by the standard way of using menstrual history together with ultrasound scans whenever available as documented in the antenatal booklet which is routinely issued to all pregnant women. Mothers should be willing to be followed together with their babies from delivery, and willing to provide the required data and biological specimens in follow-up visits for two years. Exclusion criteria will be the presence of severe maternal mental health disorders, rendering the women incapacitated to provide informed consent or comply with study procedures as assessed by the study Clinicians.

\section{Sample size and statistical power}

The composite primary endpoint of our study is the comparison of stillbirths and mortality in HEU versus HUU children until two years of age. In Zimbabwe, infant mortality rates of 50 per 1000 live births in the first year and 5 deaths per 1000 live infants in the second year of life are expected. In the pre-ART era, a 3.2-3.9fold higher mortality in the first year of life and a 2-fold higher mortality in the second year of life was observed $[37,83]$. Mortality of HEU in the Option B+ era with more effective HIV treatment might now be improved and in a conservative estimation, we assumed a 2-fold increase in mortality in HEU infants within the first two years of life.

We therefore expect $5.5 \%$ mortality in HUU infants and $11 \%$ in HEU infants. According to our power analysis using G*Power3 [84], a sample size of 1198 pregnant women will be required to detect such a difference with a power of $90 \%$ and a significance level of 0.05 in a two-sided analysis. We therefore, will opt for a sample size of 1200 pregnant women, 600 with and 600 without HIV infection.

\section{Selection of participants}

Potential participants will be identified during routine antenatal care visits at any of the four selected City of Harare Polyclinics. The potential participants will be briefed on the study and those who would have verbally agreed to participate in the study will be given the participant information sheet in the language of their choice, either in English or vernacular Shona to ensure full comprehension of the study aims and expected activities using the language that the participant understands best. Participation is voluntary and women will be free to withdraw at any time during the course of the study. Literacy is nearly universal in Zimbabwe [85] and all potential participants should be able to read and comprehend the informed consent form. However, in cases of illiterate study participants, consent will be 
documented by clearly impressing the right thumbprint on the signature page of the consent form. The actual process of right thumb printing will be witnessed by the study participant's literate relative of her choice who will print his or her name on the informed consent form and will also sign as a witness in the presence of the study team member.

No payment to research participants is required by Zimbabwean law and hence no formal payments to participants will be made for this study. However, research participants will be reimbursed US $\$ 5$ to cover travel expenses at every study visit and offered refreshments during the waiting time that will range from 30 to $60 \mathrm{~min}$. The study team will offer health education and counselling on pregnancy, delivery and childcare on a continuous basis on each study visit.

\section{Mothers' questionnaires procedures and measurements}

A midwife will administer a structured questionnaire to all pregnant women at enrolment aiming at a comprehensive clinical, behavioural and environmental characterization. Specific questions will address sexual behaviour and reproductive health issues including sexually transmitted diseases and contraception use. General health, health seeking behaviour, maternal stress and drug/herbal use will be assessed. To address hygiene, specific questions on sanitation (type and number of toilets, sewage system), drinking water, type of energy used (indoor pollution), type of floor(s) in the house, number of rooms used for sleeping by the family and the number of individuals sharing a single room will be asked. Economic information comprising employment status, family monthly income, food security, diet, monthly money set aside for food, healthcare, cooking fuel and savings will be assessed. Ownership of agricultural land or household assets including radios, televisions, mobile or fixed telephones, refrigerators, bicycles, motorcycles or scooters, and cars will provide additional information regarding social economic status. Further questions will address maternal life style such as alcohol use, smoking, sleeping habits, physical activities, domestic violence and support from spouse/partner including knowledge, beliefs and practices in relation to patterns of seeking health care services, see Tables 4 and 5 .

In HIV-infected mothers, ART use, regimen and date for commencement, co-infections and issues related to HIV status disclosure and stigma will be recorded. The information will be verified using clinical records in the maternal antenatal booklet.

A significant fraction of HIV-infected women will be unaware of their HIV status and therefore will be ART naïve [86]. In these women, ART will be initiated upon first presentation at the antenatal clinic, coinciding with enrolment into our study. Due to the unfortunate scenario of late antenatal bookings some women will therefore commence ART late or very late in pregnancy during labour. However, other women will be on ART even before conception. This provides the opportunity to study the impact of different durations of ART exposure (as a continuous variable based on gestational age at ART initiation) on birth and infant outcomes. Other than the in utero exposure, infants' exposure to ART will continue throughout the breastfeeding period since mothers are encouraged to breastfeed regardless of their HIV status.

\section{Physical examination}

At enrolment, the study midwife will perform a full physical examination, blood pressure checks, assessment of oedema and anthropometry. World health organisation (WHO) clinical staging will be done for all HIVinfected women. The examination will also include measurement of symphysis fundal height (SFH) for calculation of gestational age in comparison with last menstrual period (LMP) that is subject to considerable margin of error, particularly late in pregnancy. The SFH will be determined by measuring the distance in centimetres $(\mathrm{cm})$ from the pubic symphysis to the highest part of the uterus.

Assessment of nutritional status will be done using standard anthropometric indices including body mass index (BMI). Mid upper arm circumference (MUAC) is an easy, non-invasive and inexpensive technique in anthropometry to detect nutritional status [87]. MUAC is considered an indicator of the body protein reserves, and unlike BMI is independent of gestational age [88]. MUAC will be used as an indicator for malnutrition, including obesity. Mother's left arm will be bent at the elbow at a 90 degree angle, with the upper arm held parallel to the side of the body. The upper arm circumference will be measured at the mid-point distance between the bony protrusion on the shoulder (acromion) and the point of the elbow (olecranon). Previous South African studies demonstrated that a MUAC of $<23 \mathrm{~cm}$, predicted a pre-pregnancy BMI of $<18.5 \mathrm{~kg} / \mathrm{m}^{2}$ and a MUAC of $>30.57 \mathrm{~cm}$, predicted a pre-pregnancy BMI of $>30 \mathrm{~kg} / \mathrm{m}^{2}$ [88]. For more practical reasons, a maternal MUAC cut-offs of $\leq 25 \mathrm{~cm}$ will be used as a marker for malnutrition. Blood pressure (BP), both systolic and diastolic will be measured after allowing the mother to rest for at least $5 \mathrm{~min}$.

\section{Maternal and infant follow-up visits}

Mothers will be reminded of their upcoming follow-up study visits by phone call or through text message. Follow-up will be scheduled at delivery, within 10 days, $6,10,14,24,36,48,72$ and 96 weeks postpartum. If a mother fails to turn up for their scheduled follow-up 
Table 4 Maternal measurements and data collection time points

$\begin{array}{ll}\text { Variables } & \text { Research visit (in weeks) }\end{array}$

\begin{tabular}{lllllllllll}
\hline Pregnancy & Delivery & 1 & 6 & 10 & 14 & 24 & 36 & 48 & 72 & 96
\end{tabular}

\section{A. Maternal life style}

1. Current alcohol use

2. Smoking

3. Living under same roof with spouse/partner

4. Current marital/ domestic violence

5. Physical activity

\section{B. Household factors}

1. Household numbers \& composition

2. Number of rooms available

3. Main source of drinking water

4. Main source of energy for cooking (household pollution)

5. Main place for cooking

6. Sleeping arrangements

Water and sanitation

7. Presents of family diarrhoeal diseases

\section{Nutritional factors}

1. Maternal number of meal a day

2. Household meals eaten per day

3. Food frequency questionnaire

4. Food security tool

5. Perceived food allergens/ adverse reactions

6. $24 \mathrm{~h}$ food recall

7. Craved foods

8. Any disorder related to food mastication and/ or retention

9. Bristol stool chart

\section{General health}

1. Use of condom and sexual behaviour

2. Past and current methods of contraception used

3. 7Health seeking behaviour

4. Tb symptoms checklist for active $\mathrm{Tb}$

5. History of $\mathrm{Tb}$ disease and treatment

6. Current and past other opportunistic infections

7. Past and current symptoms of sexually transmitted infections

8. Past or current hypertension

9. Past or current stress

10. Baby blues assessment tool

11. Depression

12. Hospitalisation in the past 3 months

13. Sick clinic visits during index pregnancy

14. Vaccinations during index pregnancy

15. Timing of antenatal booking, number of subsequent visits

16. Knowledge of pregnancy disorders that warrant immediate hospitalization

17. Concurrent medication and supplements

$\checkmark$ 
Table 4 Maternal measurements and data collection time points (Continued)

\begin{tabular}{|c|c|c|c|c|c|c|c|c|c|c|c|}
\hline \multirow[t]{2}{*}{ Variables } & \multicolumn{11}{|c|}{ Research visit (in weeks) } \\
\hline & Pregnancy & Delivery & 1 & 6 & 10 & 14 & 24 & 36 & 48 & 72 & 96 \\
\hline 18. Concurrent herbal and traditional medication & $\checkmark$ & $\checkmark$ & & $\checkmark$ & & & $\checkmark$ & & & & $\checkmark$ \\
\hline 19. Use of sexual enhancing herbs/ substances & $\checkmark$ & & & & & & $\checkmark$ & & & & $\checkmark$ \\
\hline 20. History of routine dental or pap smear checks & $\checkmark$ & & & & & & $\checkmark$ & & & & $\checkmark$ \\
\hline 21. Anthropometric measurements (BMI, MUAC)) & $\checkmark$ & $\checkmark$ & $\checkmark$ & $\checkmark$ & $\checkmark$ & $\checkmark$ & $\checkmark$ & & & & $\checkmark$ \\
\hline 22. Systolic and diastolic BP and pulse measurements & $\checkmark$ & $\checkmark$ & $\checkmark$ & $\checkmark$ & $\checkmark$ & $\checkmark$ & $\checkmark$ & & & & $\checkmark$ \\
\hline 23. General physical examination (e.g. oedema) & $\checkmark$ & $\checkmark$ & $\checkmark$ & $\checkmark$ & $\checkmark$ & $\checkmark$ & $\checkmark$ & & & & $\checkmark$ \\
\hline
\end{tabular}

24. Last date of menstruation

\section{E. HIV-infected only: ART use, duration, disclosure \& adherence}

1. ART use regimen, duration, switching of regimens

2. Presence of adequate supplies

3. ART side effects

4. Non-adherence issues

5. Disclosure of HIV status

6. Stigma experience

7. WHO clinical staging for the HIV-infected

$$
\text { s }
$$

F. Clinical data collected at delivery

1. Mode of delivery

2. Duration of labour

3. Live and stillbirths

4. Term/ preterm delivery

5. Pregnancy outcome

6. Length of stay in hospital/ clinic after delivery

7. Obstetric related complications

8. Time of previous ART intake for HIV-infected mothers

\section{G. Biological specimen collection in the 3rd trimester}

\section{Stool}

i) Intestinal helminths testing

ii) Microbiome profiles (sub-studies)

\section{Urine}

i) Urinalysis and storage microbiome

\section{Blood}

i) Serology, molecular genetics, HIV, CMV, HBV, syphilis

ii) TB QuantiFERON gold (sub-study)

iii) Full blood counts

iv) Infant vaccine titres

v) Biochemistry

a. Dyslipidaemia

b. Kidney function tests

c. Liver function tests

i) Vitamin D

ii) HbA1c, random glucose

iii) Cytokine profiles

iv) CD4 counts 
Table 4 Maternal measurements and data collection time points (Continued)

\begin{tabular}{|c|c|c|c|c|c|c|c|c|c|c|c|}
\hline \multirow[t]{2}{*}{ Variables } & \multicolumn{11}{|c|}{ Research visit (in weeks) } \\
\hline & Pregnancy & Delivery & 1 & 6 & 10 & 14 & 24 & 36 & 48 & 72 & 96 \\
\hline v) HIV RNA load & $\checkmark$ & & & & $\checkmark$ & & & & & & $\checkmark$ \\
\hline vi) CMV DNA load & $\checkmark$ & & & & & & & & & & $\checkmark$ \\
\hline \multicolumn{12}{|l|}{ vii) HBV DNA load } \\
\hline \multicolumn{12}{|l|}{ viii) Host genetic susceptibility } \\
\hline ix) Immunometabolomics & $\checkmark$ & $\checkmark$ & $\checkmark$ & $\checkmark$ & $\checkmark$ & $\checkmark$ & $\checkmark$ & $\checkmark$ & $\checkmark$ & $\checkmark$ & $\checkmark$ \\
\hline \multicolumn{12}{|l|}{ H. Delivery bio-specimens } \\
\hline 1. Placental pathology in latent Tb (sub-study), microbiome & & $\checkmark$ & & & & & & & & & \\
\hline 2. Amniotic-fluid co-infections, alcohol levels, microbiome & & $\checkmark$ & & & & & & & & & \\
\hline 3. Breast milk (lipid profiles and microbiome, CMV viral load), microbiome & & $\checkmark$ & $\checkmark$ & $\checkmark$ & $\checkmark$ & $\checkmark$ & $\checkmark$ & $\checkmark$ & $\checkmark$ & $\checkmark$ & $\checkmark$ \\
\hline \multicolumn{12}{|l|}{ I. Spouse/ intimate partner factors (as reported by mothers) } \\
\hline 1. Age & $\checkmark$ & & & & & & & & & & \\
\hline 2. Occupation & $\checkmark$ & & & & & & & & & & $\checkmark$ \\
\hline 3. Previous marital status & $\checkmark$ & & & & & & & & & & \\
\hline 4. HIV status, ART usage & $\checkmark$ & & & & & & & & & & $\checkmark$ \\
\hline 5. Participation in pregnancy, ante & $\checkmark$ & & & & & & & & & & $\checkmark$ \\
\hline 6. Participation in child care & $\checkmark$ & & & $\checkmark$ & & & & & & & $\checkmark$ \\
\hline
\end{tabular}

ART antiretroviral therapy, BMI body mass index, CD4 cluster of differentiation-4, CMV cytomegalovirus, EPI The expanded program of immunisation, MUAC mid upper arm circumference, $H B A 1 c$ glycated haemoglobin, $H B V$ hepatitis $B$ virus, $H C V$ hepatitis $C$ virus, HLA human leukocyte antigen, HIV human immunodeficiency virus, KIR killer cell immunoglobulin-like receptor, SGA small for gestational age, TB tuberculosis, WHO world health organisation

appointments, attempts to contact her or her next of kin by phone and/ or home visits will be made strictly adhering to the documented mother's preferences. Data and samples will still be collected provided the missed visit can be rearranged within the following seven days. In case of two consecutive missed visits without communication, study discontinuation will be discussed with the mother.

Information on place, date and mode of delivery will be extracted from "Road to Health Child' cards" issued at birth for monitoring growth, vaccinations records until 5 years of age. Longitudinal infant feeding practices and comprehensive information on health, development and environment will be collected. Extensive questionnaires similar to the one administered at enrolment will be re-administered at 6 , 12, 18 and 24 months. Physical examinations of mothers will be performed until week 6 after delivery and at exit. For infants physical examinations will be done at every visit. Sick infants will be seen by the study Paediatrician. Study procedures also include bio-sampling of blood, breast milk and stool at every study visit.

\section{Adverse birth outcomes and infant mortality}

The key outcome of this study is mortality of infants assessed by the composite endpoint of stillbirth (gestational age at birth $\geq 20$ weeks) and infants who die during the first two years of life.
Adverse birth outcomes will include the need for resuscitation at birth due to birth asphyxia or respiratory distress syndrome. These conditions can be accurately diagnosed by a midwife. Birth asphyxia will be defined as any medical condition resulting in decreased or discontinued supply of oxygen to a newborn infant before, during or soon after birth. No formal paediatric assessment will be performed at birth; therefore, accurate diagnosis of other paediatric conditions will not be feasible at this point. Other adverse outcomes at delivery will include preterm birth. WHO criteria will be applied in calculations regarding infants' anthropometric measurements [89]. Gestational age will be divided into early preterm (20-31 weeks), late preterm (32-36 weeks), term (at least 37 weeks) and post term birth ( $>42$ weeks of gestation). Additional adverse outcomes are a low Apgar score at 5 min $(<7)$, small for gestational age (SGA, i.e. weight/ length below the $10^{\text {th }}$ percentile for gestational age), low birth weight (LBW) $(<2500 \mathrm{~g}$, weighed within the first hour of life, before significant postnatal weight loss would have occurred), very LBW $(<1500 \mathrm{~g})$, extremely low birth weight $(<1000$ $\mathrm{g})$, foetal macrosomia (birth weight $>4000 \mathrm{~g}$ ), microcephaly (head circumference $<2$ standard deviation (SD) from the mean) and multiple births. A brief physical examination will be performed by the midwife regarding structural birth defects (malformations, e.g. extra digits). All infants with suspicious findings 
Table 5 Infant data and health assessment tool

Exposure and data collection points (delivery $=0$ time point)

a) Infant in utero exposures

1. HIV exposure in utero/ postpartum

2. Antenatal dysbiosis, microbiome

3. Congenital co-infections; HBV, HCV, CMV, syphilis

4. Alcohol exposure (foetal alcohol syndrome)

5. Food quantity and quality, antenatal diet, maternal BMI

6. Allergens, food, animal dander

7. Indoor pollution (paraffin stove cooking in one room/smoker)

8. Household factors water/sanitation (quantity/quality)/

\section{b) Delivery \& Postpartum Data}

1. Delivery date, gender, SGA, Apgar score, congenital abnormalities

2. Weight, head circumference and length (MUAC from 6 weeks)

3. Infant morbidity, sick clinic visits, hospitalisations, atopic dermatitis

4. Infant mortality

5. EPI immunisation compliance

6. Any medication being taken

\section{c) Infant developmental assessment tools}

\section{Denver tool}

2. Mullen tool (neurodevelopmental sub-study)

\section{d) Biological specimen collection}

\section{Cord blood}

2. Blood and dried blood spots

a) Vertical transmission of HIV, CMV, HBV, syphilis

b) EPI vaccine titres

c) Plasma immune activation biomarkers

d) Systemic plasma Inflammation biomarkers and trends

e) Endothelial dysfunction biomarkers

f) Immunometabolomics

g) Biomarkers of intestinal structure and function (permeability, microbial translocation)

h) Food allergens and atopic dermatitis sensitisation trends

i) Full blood counts and clinical biochemistry

j) HIV viral load (in infected individuals)

k) Pathogen genetic diversity and Host infection genetics
Research visit (weeks)

\begin{tabular}{llllllllll}
\hline 0 & 1 & 6 & 10 & 14 & 24 & 36 & 48 & 72 & 96
\end{tabular}

$\begin{array}{llllllllll}\checkmark & \checkmark & \checkmark & \checkmark & \checkmark & \checkmark & \checkmark & \checkmark & \checkmark & \checkmark \\ \checkmark & \checkmark & \checkmark & \checkmark & \checkmark & \checkmark & \checkmark & \checkmark & \checkmark & \checkmark \\ \checkmark & \checkmark & \checkmark & \checkmark & \checkmark & \checkmark & \checkmark & \checkmark & \checkmark & \checkmark \\ \checkmark & \checkmark & \checkmark & \checkmark & \checkmark & \checkmark & \checkmark & \checkmark & \checkmark & \checkmark \\ \checkmark & \checkmark & \checkmark & \checkmark & \checkmark & \checkmark & \checkmark & \checkmark & \checkmark & \checkmark \\ \checkmark & \checkmark & \checkmark & \checkmark & \checkmark & \checkmark & \checkmark & \checkmark & \checkmark & \checkmark \\ \checkmark & & & & \checkmark & & & & \checkmark\end{array}$

$B M I$ body mass index, CMV cytomegalovirus, EPI The expanded program of immunisation, MUAC mid upper arm circumference, HBV hepatitis B virus, HCV hepatitis $C$ virus, SGA small for gestational age

regarding birth defects will be followed up by a team of four board certified study Paediatricians.

\section{Infant growth}

Growth will be expressed as $\mathrm{Z}$ scores according to WHO definitions [89]: Weight-for-age (WAZ), heightfor-age (HAZ), weight-for-height (WHZ) and headcircumference-for-age (HCAZ). Growth outcomes will be evaluated as continuous variables (attained Z-score and change in Z-score between visits). In addition, the following categorical outcomes will be assessed:

- Moderate wasting, $\mathrm{WHZ}<-2$

- Stunting, HAZ $<-2$

- Severe stunting, $\mathrm{HAZ}<-3$

- Underweight, WAZ $<-2$

- Microcephaly, HCAZ<-2. 
Infant MUAC will be measured from 6 weeks of age and sensitivity, specificity, positive predictive values, and negative predictive values of the MUAC for stunting, underweight, wasting, anaemia and adverse neurodevelopment in HEI, HEU and HUU infants aged $0-<6$ months, $6-<$ 12 months and $12-24$ months will be determined. WHZ will be used as the gold standard for wasting.

\section{Assessment of infant morbidity}

Morbidity diaries will be issued to mothers at delivery. Medical professionals unrelated to the study (e.g. Municipal primary health nurses) will also document medical reports in the morbidity diary during sick visits and/or hospitalizations. These will include: neonatal hypoglycaemia, neonatal jaundice, infant anaemia, skin rashes, congenital infections, vertical transmission of infections over the 2 years, any hospitalisation (frequency and duration), sick visits (dates and duration), documented local inpatient treatments, stunting, wasting and abnormal neurodevelopment. After episodes of illnesses, follow up notes will be recorded in the diary by the study nurse. The mother will also continuously assess infant well-being and will be encouraged to document any perceived child sickness in the morbidity diary. Contents of morbidity diaries will captured, pictured/photocopied at each study visit.

\section{Infant development}

Neurodevelopmental outcomes will be evaluated from six weeks until two years of age using the Denver II screening tool [90]. The Denver II tool enables assessment of gross and fine motoric abilities, development of language, social skills, attention span, general compliance and fearfulness. In addition, infant developmental milestones (e.g. timing of teething, first sitting, walking or talking) will be recorded. No neurological assessment tool has been formally validated in Zimbabwe; the Denver tool will be used since it can be conveniently applied by the study nurse [90]. Our study Paediatricians' clinical experiences indicate that the tool is appropriate without adjustment for the Zimbabwean setting. For detailed neurodevelopmental and cognitive assessment, the Mullen tool [91] will be used in a sub-study at 12 and 24 months of age.

\section{Maternal biosamples}

Biological specimens including whole blood, plasma and serum, stool, and breast milk will be collected at all visits; cord blood, amniotic fluid and placenta will be collected at delivery. Sensitive samples (stool, milk, urine) will be placed at 4 degree Celsius $\left({ }^{\circ} \mathrm{C}\right)$ for no longer than $4 \mathrm{~h}$ before processing. All samples will be stored in a bio-bank at $-80^{\circ} \mathrm{C}$ within a maximum of $6 \mathrm{~h}$ after acquisition.
Different lab tests will be done (Table 3). Most tests will apply for all mothers regardless of their HIV status for comparison of disease burden between both groups.

HIV-uninfected mothers will be continuously counselled and retested for HIV infection every 6 months until 2 years after delivery (Table 3 point i.). Seroconverting women will be referred to the national HIV prevention program for immediate commencement of ART and immunological and virological monitoring.

\section{Infant blood samples}

Infant venous blood will be collected whenever possible at 7-10 days and 24 months for full blood counts. Whenever possible, plasma samples will be stored. The volume of blood collected will be within recommended amounts depending on the weight of the infant (i.e. $\leq 1-$ $5 \%$ of total blood volume over $24 \mathrm{~h}$ and $\leq 10 \%$ over 8 weeks) [92]. Blood will not be collected from severely sick infants and those with suspected severe anaemia according to clinical assessment.

Dried blood spots (DBS) will be collected wherever possible at every visit using whole blood samples or a needle prick puncture of the heel. 3-5 drops of blood will be collected and dried on Whatman filter paper and stored at $-20^{\circ} \mathrm{C}$.

HIV exposed infants will also be tested for HIV within 10 days of life, at weeks $10,14,24,36,48,72$ and 96 or until cessation of breast feeding, whichever comes first.

\section{Summary of sub-studies}

\section{Gut microbiota sub-study (longitudinal analysis)}

Chronic intestinal maladaptive and inflammatory alterations in a resource limited setting with inadequate nutrition and hygiene are summarized as environmental enteric dysfunction (EED). EED is characterized by a delayed and aberrant maturation of the intestinal microbiota [93, 94], ultimately resulting in dysfunction and failure of the microbiota metabolic organ [95]. Understanding microbiota maturation will likely be key to the pathogenesis of EED. HIV infection and ART use have also been associated with a disturbed gut microbiota [96] and might further aggravate EED.

For in-depth microbiota analysis, sequential stool samples taken from MIPs will be used to perform 16S rRNA sequencing for assessment of phylum and operational taxonomic unit composition with $\geq 97 \%$ sequence identity, as well as microbial diversity [97]. In selected samples bacterial full genome metagenomics shotgun sequencing to identify the microbiota metabolic potential (i.e. bacterial genes present [96] will be done. Further, mass spectrometry will be performed for analysis of small intestinal content (metabolome) $(83 ; 84)$ including assessment of markers of microbial translocation across the damaged gut wall [98] such as lipopolysaccharide 
(LPS), a component of gram-negative bacterial cell walls, a biomarker of microbial translocation [99], with intestinal fatty acid binding protein (I-FABP) as a biomarker for enterocyte damage [100]. Continuous passage of immuno-stimulatory LPS from the intestinal lumen into the systemic circulation sustains activation of both innate and adaptive immunity causing systemic immune activation through activation nuclear factor kappa beta $(\mathrm{NF}-x \beta)$ protein complex that controls transcription of DNA in cytokine production [101]. Protective factors include immunoglobulin M (IgM), IgG, and IgA specific for the LPS core antigen and endotoxin core antibodies (EndoCAb) [102]. Microbial translocation has been associated with HIV clinical progression and early onset of non-AIDS comorbidities. How microbiota profile is affected by HIV /ART exposures and cotrimoxazole prophylaxis in settings of poverty and malnutrition remains to be explored with respect to infant growth, development and susceptibility to infectious diseases. Use of probiotics and prebiotics can be potentially used to modify the disturbed /imbalanced bacterial profile in the gastrointestinal tract of HEU infants. This microbiota sub-study will involve sampling of $\geq 100$ women in pregnancy and MIPs within 10 days of life, at weeks 6,10 , 14, 24, 36, 48, 72 and 96. Biosamples include MIPs plasmaand stool samples, including breast milk. See Table 3 xxi, xxii, xxiii and xxiv for details.

\section{Immuno-metabolomics sub-study (longitudinal analysis)}

Interference with lipid, glucose amino acids metabolism is another mechanism for ART toxicity. This sub-study aims to investigate plasma inflammatory immune activation markers as risk factors for adverse pregnancy outcomes in HIV-infected women and subsequent impaired infant growth and development. For this study-study we will select a sub group of HIV-infected pregnant women with long-term (>7 months), medium-term (1-7 months) and no/ short-term (no or $<1$ months) ART use and uninfected women as controls. We will test for systemic inflammatory immune activation markers in MIPs plasma samples at enrolment, delivery, 10 days, 6 , 14, 24, 48 and 72 weeks. Enzyme linked immuno assay (ELISA)-based multiplex testing by Luminex technology will be used to measure chemokines and cytokine levels including, B cell-attracting chemokine 1, brain-derived neurotrophic factor, interferon gamma inducible protein 10 , monokine induced by gamma interferon, monocyte chemo-attractant protein 1 , macrophage inflammatory protein-1 $\beta$, tumour necrosis factor alpha, matrix metalloproteinase-1, transforming growth factor beta, interferon gamma, interleukin (IL)-1 $\beta$, IL-2, IL-4, IL-6, IL-7, IL-10, IL-12, IL12p70, IL-17A, IL-27, INF- $\gamma$, cluster of differentiation (CD) 30 and CD40. See Table 3 xxviii for details.
To assess the metabolome and mitochondrial dysfunction, mass spectrometry techniques will be used to measure a wide range of metabolites including reactive oxygen species, triglycerides, diacylglycerides, cholesterol, phospholipids, fatty acids, peroxidized lipids and oxylipids. Metabolite levels will be correlated to pregnancy outcome and with infant growth (LBW, SGA, stunting wasting) and infants' immune responses to vaccines. This metabolomics component will involve convenient sampling of $\geq 55$ women in pregnancy and respective MIPs within 10 days of life, at weeks 10, 14, 24, 36 and 48. Biosamples include MIPs plasma samples. See Table 3 xxix for details.

\section{Cell-mediated immunity/glucose metabolism sub-study}

HIV infects activated but not resting $\mathrm{CD}^{+}{ }^{+}$lymphocytes, and hence the need to understand how host nucleotide, glucose, lipid, amino acid metabolism including the respective cell oxidative stress support HIV RNA replication [103]. Maternal HIV infection and ART use can cause foetal immune-metabolic dysregulation [104] which may contribute to impaired growth and long-term abnormal immune development. Tlymphocyte maturation and natural killer (NK) cell numbers or/and functions are altered in HEU new-borns and these abnormalities persist over time [105-107] causing increased mortality and morbidity. This sub-study aims to determine the role of maternal HIV infection on NK cell surface markers and nutrients transporters expression of infants with long-term (> 7 months), mediumterm (1-7 months) and short-term ( $<1$ months) in utero ART exposures compared to their HUU counterparts. We will isolate peripheral blood mononuclear cells (PBMCs) for cell staining and analysis. Measurements require samples with sufficient blood volume of $\geq 2 \mathrm{~mL}$ and hence assays will be done later, after 12 months of age. We will determine numbers and function of $\mathrm{T}$ lymphocytes, as well as NK cells as previously described [108]. This longitudinal sub-study will involve convenient sampling of $\geq 160$ infants at weeks 48 and 96 of age. See Table 3 xxvi for details.

\section{Latent tuberculosis co-infection sub-study (longitudinal analysis)}

Co-infection with Mycobacterium tuberculosis (MTB) is an independent risk factor for maternal mortality in HIV infection [8]. We hypothesize that undiagnosed latent $\mathrm{TB}$ can partially explain increased infant mortality in resource limited settings. Diagnosis of TB can be a clinical challenge. Sputum tests for TB are generally falsenegative in a significant fraction of patients due low sensitivity [109]. Tuberculin skin test (TST) has been used to screen for latent TB; however, due to the interaction with BCG vaccine [110] which is administered routinely 
at birth in Zimbabwe, TST specificity may be greatly reduced in our study population. To test for latent TB, IFN- $\gamma$ release assays (IGRAs), unaffected by BCG vaccination will be used in a subgroup of HIV- infected and -uninfected women. IGRAs measurements and size of TST lesions will be correlated with adverse maternal and infant outcomes with the aim to develop future more sensitive latent $\mathrm{TB}$ diagnostic algorithms for pregnant women in resource limited settings.

This latent TB co-infection sub-study will involve convenient sampling of a total of 400 HIV-infected anduninfected women. TST will be done in pregnancy and at 6 weeks postpartum with concurrent collection of blood for IGRAs testing. Further, placental samples will be tested for histological lesions suggestive for MTB inflammation. Placenta samples will be randomly collected from $\geq 100$ mothers at delivery. See Table 3 xxvii for details.

\section{Maternal stress sub-study (longitudinal analysis)}

Perinatal stress has been linked to alterations of the hypothalamic-pituitary-adrenal axis activity of the offspring leading to vulnerability later in life. Maternal stress results in increases in cortisol, norepinephrine and inflammation with implications in infant health. Causes of maternal stress include diagnosis of HIV, intimate partner violence, low socio-economic status, being a single parent, unplanned pregnancy, food insecurity including bereavement. This sub-study will assess prevalence, risk factors and coping mechanism of maternal stress among HIV -infected and -uninfected pregnant women. In this maternal stress sub-study, a perceived stress tool will be administered to $\geq 400 \mathrm{HIV}$ - infected and - uninfected women in pregnancy and at 6 weeks postpartum.

Stress hormone, cortisol production has a circadian rhythm with levels peaking in the early morning and dropping to the lowest at night, with levels rising independently of circadian rhythm in response to stress [111, 112]. Studies have shown high correlations between serum and salivary cortisol, thus salivary cortisol levels are a reliable estimate of serum cortisol levels [113]. Single salivary cortisol measurement are unreliable as biomarkers for stress since the circadian rhythm of cortisol secretion is not captured [114]. We will therefore measure morning and evening infant saliva cortisol at 6 months of age and correlate levels to child health and their long term mental health and neurocognitive outcomes. Infant cortisol levels will be measured in salivary swabs at week 6 of age. The mothers, following instructions given by the study nurse will collect the infant saliva swabs for cortisol measurements. See Table 3 xxviii for test details.

\section{Neurodevelopmental outcomes (longitudinal analysis)}

Neurodevelopmental deficits such as language impairment are more severe and more prevalent in HEI and HEU infants compared with HUU controls in resource limited settings [115]. This sub-study will be evaluating potential long-term neurodevelopmental sequelae related to extended ART exposure. Therefore, a subgroup of HEU, HEI and HUU infants will have extended testing for cognitive performance and neurodevelopmental defects using the Mullen tool [91] at 12 and 24 months correlating with socio-economic status and infections. A total of $\geq 300$ HEU and HUU infants will be conveniently sampled and followed up.

\section{Immunotoxicology sub-study (longitudinal analysis)}

Exposure of pregnant women and their infants to mycotoxins is a major public health concern, as this may be associated with nutritional deficiencies and growth retardation. Mycotoxins, especially carcinogenic aflatoxins b1 (AFB1), produced by Aspergillus flavus are normally present in poorly stored food grains. Not much has been done to determine the maternal burden of mycotoxins, more so in this high HIV prevalence setting. At least in porcine models exposure to mycotoxin, fumonisin B1 has been shown to alter the immune responses by decreasing the level of IL-8 [116].

This sub-study hypothesises that high exposures to mycotoxin causes maternal immune-dysregulation that in turn causes adverse birth outcomes and poor infant health. The main aim is to identity useful biomarkers for interventions to mitigate mycotoxin exposure associated adverse birth outcomes and poor health in infants. Maternal random urine, amniotic fluid and longitudinal breast milk samples will be analysed for at least 20 mycotoxin biomarkers, including both the parent mycotoxins and mycotoxin metabolites. High-performance liquid chromatography tandem mass spectrometry method with modifications will be used as previously described [117]. A total of $\geq 400 \mathrm{HIV}$ - infected and -uninfected women will be randomly selected in pregnancy, and followed up at delivery and 24 months after delivery.

\section{Helicobacter pylori sub-study (longitudinal analysis)}

The development of chronic gastritis, recurrent peptic ulcers including gastric cancers has been associated with H. pylori infections [6]. Risk factors include low socioeconomic status, poor hygiene, and overcrowding [118]. The prevalence of $H$. pylori infection is persistently higher in developing countries where more than $70 \%$ of the adult population is colonized with $H$. pylori, with > $50 \%$ children acquiring it by the age of 10 [119]. Most published data on $H$. pylori infection are largely centred on adults. Thus, there are significant knowledge gaps on the risk factors of initial $H$. pylori colonization, trends 
and persistence of the infection in children. This substudy aims to compare timing and trends of $H$. pylori colonisation and immunity among HUU and HEU infants from birth until 2 years of age, with the aim to develop preventive measures to reduce early life infections. Random sampling of $\geq 100$ women in pregnancy will be done. Follow up will be within 10 days of life, at weeks 10, 14, 24, 36, 48, 72 and 96 with collection of MIPs stool samples for testing of $H$. pylori antigen and antibodies using simple ELISAs. See Table 3 xxix for details.

\section{Study time frame}

Pregnant women have been enrolled into the UZ-CHS Birth Cohort study from February 2016 until June 2019. MIPs will be followed for 2 years, with an expected study completion date in June 2021. Long-term follow-up studies until school-going age and adolescence are in planning.

\section{Data flow and analysis}

Data is being entered at the study sites into paper CRF that will subsequently be entered into a Research Electronic Data Capture (REDCap) secure web with regular backups. Data will be analysed using SPSS (version 17.0, Chicago, IL) or other analysis tools using standard statistical methods for parametric or non-parametric testing or analysis of categorical outcomes, whatever appropriate.

The main endpoint of our study, the composite endpoint of stillbirth and mortality until two years of age of HEU vs. HUU infants will be corrected for confounders in a multivariable logistic regression analysis. In this analysis, we aim to correct for socio-demographic parameters (e.g. maternal age), descriptors of the current and past reproductive history (e.g. number previous pregnancies, current twin/multiple pregnancy), maternal comorbidities (e.g. hypertension, metabolic syndrome, infectious comorbidities), economic situation (marriage and employment state, family income), maternal nutrition (e.g. number days without food, MUAC) and hygiene (number of days without running water). For selection of confounders, individual parameters from the database will be tested in a univariate analysis. If significance is detected $(p<0.1)$, the parameter will be included in a multivariable analysis with parameter elimination for optimization of the Akaike information criterion. Confounders for maternal outcomes will be selected using a similar strategy.

For secondary outcomes, Cox proportional hazard models will be used for time-dependent variables, also controlled for confounders in multivariable analyses. Predictors of secondary outcomes will also be analysed using hierarchical all-against-all clustering [120]. A pvalue $<0.05$ will be considered significant. We will provide nominal $p$-values and Bonferroni-corrected $p$ values in case of a multiple testing situation.

\section{Discussion}

The UZ-CHS Birth cohort is a prospective study in a resource limited setting following up HEU and HUU infants, assessing their health and development within the first 2 years of life. The composite primary endpoint is stillbirth and infant mortality within the first two years of life in HEU versus HUU children. Maternal mortality from enrolment until two years after birth in HIV infected vs. HIV uninfected participants is another primary endpoint of this study. Secondary endpoints include a range of maternal, birth and infant outcomes. It provides a unique opportunity to answer a multitude of research questions that build a comprehensive understanding of the impact of HIV and comorbidities, ART use including other maternal and infant environmental factors on infant mortality, morbidity, growth and immune/ neurodevelopment. The potential output will impact on policy and practice regarding perinatal care for mothers and infants in resource limited settings. The extensive data on maternal nutrition and hygiene, sexual and reproductive behaviour, HIV disease characteristics, infectious disease complications and the extensive bio-sampling of MIPs provide opportunities for a number of sub-studies to better understand how environmental exposures modulate immune system, microbiota and other physiological parameters in mothers and their infants.

Health of HEU infants is of great concern and great public health importance in SSA; however, the reason for poor outcomes in HEU is not well understood. Besides exposure to HIV and ART, HEU infants might differ from HUU by exposure to other infections and maternal co-morbidities and other socio-economic measures might also differ. For these reasons, a comprehensive study is needed. Results of our analyses might identify early markers for poor outcome and help to develop specific interventions for HEU infants. For instance, if the response of HEU and HUU infants to vaccines would differ, the vaccination plan for HEU infants could be modified [121]. On the other hand, the possibility that exposure to HIV in utero would prime the immune system with lasting effects after birth warrants further studying and could yield in insights regarding immune development.

However, Option B+ strategy does not completely eliminate MTCT and among the offspring of 600 HIVinfected mothers, approximately $30 \mathrm{HEI}$ infants are expected (Fig. 1). Mortality of these infants is expected to be significantly higher compared to HEU infants, warranting separate analyses of this group for all clinical analyses and biomarker assays. 
1200 eligible pregnant women

Demographics, physical examinations, history of STIs, assessment of nutritional status, co-infections, NCDs

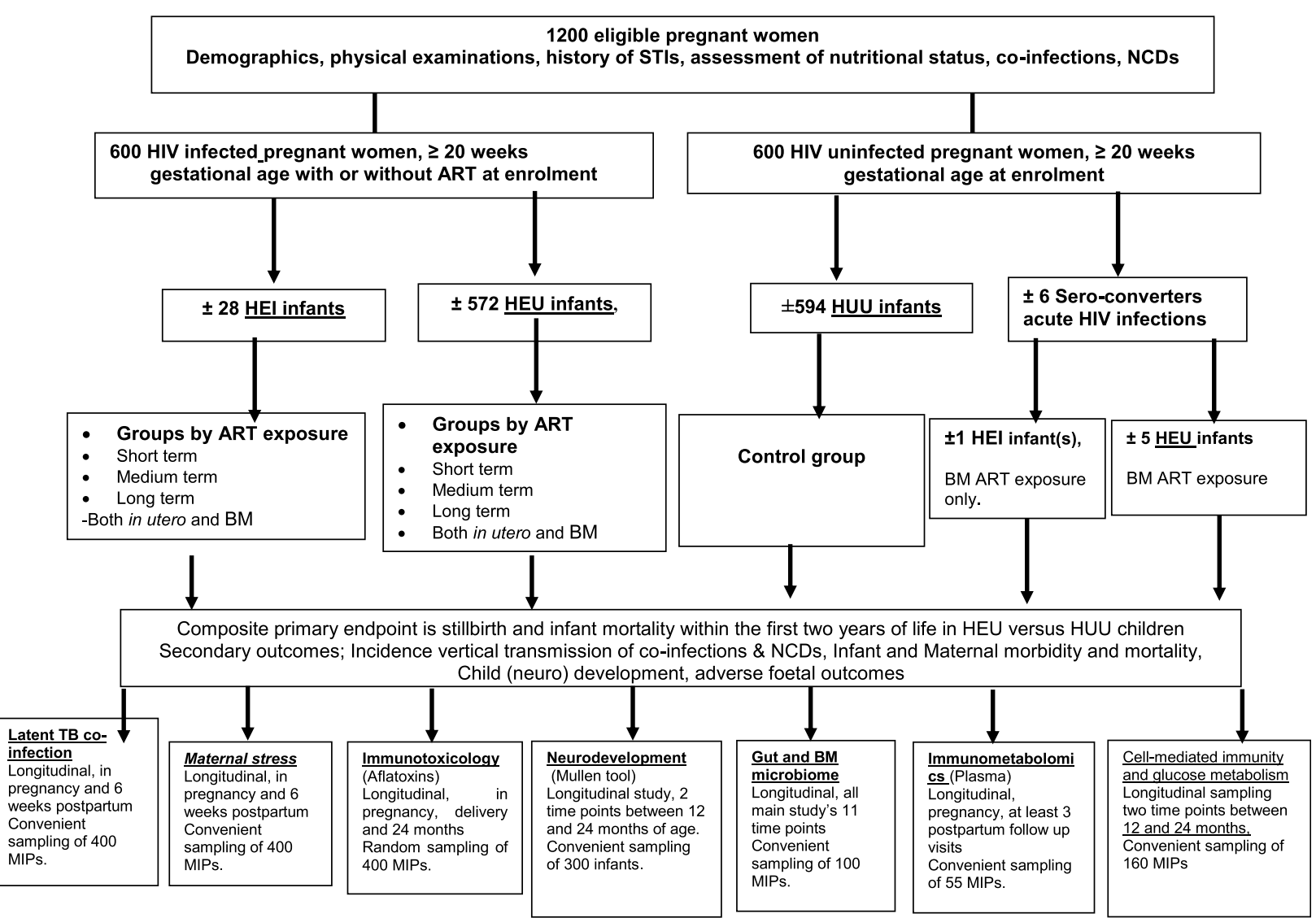

Fig. 1 Main Study and sub-studies Flow Diagram. ART: Antiretroviral therapy, BM: Breast milk, Co-infections include hepatitis B virus, hepatitis C virus, CMV:cytomegalovirus, and intestinal parasites. HEl: HIV exposed and infected, HEU: HIV exposed but uninfected HIV: Human immunodeficiency virus, HUU: HIV unexposed and uninfected, MIPs: Mother -infant pairs, NCD: Non-communicable diseases and these include hypertensive disorders, malnutrition and diabetes, STIs: Sexually transmitted infections

Introduction of ART has dramatically decreased the MTCT rates by more than 10-fold, an important medical success $[2,122,123]$. However, use of ART in pregnancy is a double edged sword and part of the burden on HEU infants might be due to adverse effects of ART. The safest ART regimens in pregnancy still needs to be determined. ART treatment plans continue to evolve and plans to replace Efavirenz with Dolutegravir are at an advanced stage but with its challenges [53]. Efavirenz has been shown to trigger apoptosis, an effect in part due to interference with mitochondrial membrane potential [48]. Continuous surveillance regarding Dolutegravir related structural birth defects can be done in future sub-studies in our cohort.

Future sub-studies of our cohort might follow infants into childhood and adolescence to assess long term immune and neurodevelopment including mental health outcomes. A further desirable future expansion might be a strictly rural observational cohort, to control for household, lifestyle and environmental confounders associated with the current urban based study.
Strength of our study includes the large number of pregnant women as well as extensive longitudinal questionnaires addressing many aspects of health, nutrition, hygiene and reproductive behaviour. Biosampling of many biomaterials at close time points from both, mothers and infants, will enable identification of biomarkers and addressing of pathomechanisms in future translational experiments. In our study, we will document timing of ART before, during and after pregnancy in detail, allowing studying the effects of foetal exposure to ART at different time points on birth outcomes and infant developments. Furthermore, our study has a comparative group of HUU infants enrolled from the same community sampled at the same time. Finally, even though Zimbabwe currently faces pronounced economic challenges, literacy is nearly universal. Research participants should understand study procedures well, and mothers will be able to document infant health in morbidity diaries and follow the study processes with high compliance. 
Limitations of our study include the noninterventional study design. Therefore, any important association identified would need to be confirmed by an interventional study. Further, gestation age estimate is based on reported last menstrual period that may be associated with recall bias and complementary use of ultrasound is missing. Moreover, due to the high prevalence of environmental risk factors for infant health related to poor socio-economic status, some specific risk factors might not be identified by our study design. Therefore, there is the possibility of a type II error for adverse effects of ART with low risk in our cohort due to a high number of additional risk factors. Finally, all our research participants reside in a rather homogeneous high-density residential area in Harare, Zimbabwe. Our results will therefore probably apply to similar resource limited settings in SSA. However, results from our cohort might not be generalizable to other more affluent urban environments or rural areas. Caution would be needed to generalize our results to industrialized countries.

In summary, we introduce the University of Zimbabwe birth cohort study, which is following up 600 HIV infected and 600 uninfected mothers and their infants in a resource limited setting in a highdensity residential areas around Harare. Acquisition of extensive clinical meta-data and comprehensive bio-sampling will enable us to answer many questions important for this study population including the health of HEU infants. This is important, as future health and wellbeing in adulthood are influenced by external environmental insults encountered during the first couple years of life.

\section{Abbreviations}

AIDS: Acquired immunodeficiency syndrome; ART: Antiretroviral therapy; CD4: Cluster of differentiation 4; CD8: Cluster of differentiation 8; CMV: Cytomegalovirus; DBS: Dried blood spots; DNA: Deoxyribonucleic acid; EPI: Expanded program on immunization; JREC: Joint Research Ethics Committee of the University of Zimbabwe and Parirenyatwa Hospital; HAZ: Height for age Z score; HCAZ: Head circumference for age Z score; HBV: Hepatitis B virus; HEU: HIV-exposed but uninfected; HEl: HIV exposed and infected; HIV: Human immunodeficiency virus; HBsAg: Hepatitis B virus surface antigen; HUU: HIV-unexposed and uninfected; LBW: Low birth weight; LMP: Last menstrual period; IL: Interleukin; MIPs: Mother-infant pairs; MTCT: Mother to child transmission; MUAC: Mid upper mid arm circumference; MRCZ: Medical Research Council of Zimbabwe; NCD: Noncommunicable diseases; PCR: Polymerase chain reaction; PMTCT: Prevention of mother to child transmission of HIV: ZHDS: Zimbabwe health demographic survey; RNA: Ribonucleic acid; SD: Standard deviation; SFH: Symphysis fundal height; SGA: Small for gestation age; SSA: Sub Saharan Africa; TB: Tuberculosis; TENOLAM-E: Tenofovir, Lamivudine and Efavirenz; USA: United States of America; UZ-CHS: University of Zimbabwe College of Health Sciences; WAZ: Weight for age Z scores; WHZ: Weight for height Z score; WHO: The World Health Organisation

\section{Acknowledgements (birth cohort team)}

The authors would like to thank the participants of the UZ-CHS birth cohort study and the research support team for their commitment, including both local and international collaborators; Professor M Altfeld, Dr. M Bunders (HPI, Hamburg, Germany), Professor S Rowland-Jones (Oxford University, United
Kingdom), Professor C Dandara (University of Cape Town, South Africa), Dr. V Mleya and Dr. J Mutambara (Midlands State University) and Dr. G Kandawasvika, Dr. P Kuona, Dr. S Chimhuya (Department Paediatrics and Child Health UZ-CHS and Mrs. R Nyamakura (Department of Nursing Science UZ-CHS). Dr. S Mtapuri-Zinyowera (National Microbiology Reference lab). Mr. P Chandiwana, Mr. C Marashiki, Ms. H Mataramvura, Ms. E Mazengera, Mr. N Taremeredzwa (Department of Immunology).

\section{Authors' contributions}

The study was conceived by KD, designed by KD, FZG, EG, AZ, KM, LRM, PC and AM. Data collection, entry and validation were done by PTM, PC, AZ, KM, and LRM overseen by KD and FZG. BM and SR performed statistical analyses and interpretation of data. The bulk of the manuscript was written by KD and BM. All co-authors substantially revised the manuscript drafts and approved the submitted version.

\section{Funding}

The study is being supported by the Wellcome trust under the University of Zimbabwe, the Southern Africa Consortium for Research Excellence (SACORE) grant number 087537/F/08/A. Supplemental sponsorships are from the Norwegian Programme for Capacity Development in Higher Education and Research for Development under the University of Zimbabwe NORHED grant (NORHED QZA-0484MWI-13/0032), the Royal Society of Tropical Medicine and Hygiene (RSTMH), GR000782, the Academy of Medical Sciences Global Challenges Research Fund Networking Grant Scheme (GCRF NGR2 10499), United Kingdom, Deutsche Forschungsgemeinschaft (DFG) BU 3630/2-1, the Botnar Foundation and the Department of Visceral Surgery and Medicine, Bern University, Switzerland. None of the funding bodies were or will be involved in the study design, data collection, data analysis, interpretation of findings and/ or manuscript writing.

\section{Availability of data and materials}

The datasets obtained during this study will be available upon request to the corresponding authors. Only encrypted data will be shared with collaborating partners using EGAcryptor in line with the current European General Data Protection Regulation effective May 25, 2018.

Results will be published in journals with scientific quality assurance, targeting open access journals whenever possible for a wider accessibility. Data sets used in published studies will be made publicly available with the respective publication.

\section{Ethics approval and consent to participate}

The UZ-CHS Birth Cohort study will comply with the ethical principles of the Declaration of Helsinki (updated 2013) and will also be conducted in compliance with the international council for harmonisation of good clinical and laboratory practice guidelines and local regulatory requirements. Ethical approval was obtained from the Joint Research Ethics Committee (JREC) of the University of Zimbabwe (JREC/18/15), the Medical Research Council of Zimbabwe (MRCZ/A / 1968), and the Research Council of Zimbabwe (SC/9). Permission was granted to use any or all of the City of Harare antenatal clinics as study sites. Since this is an observational study, the need for a data and safety monitoring board was waved. All study participants will provide written informed consent. Permission for storage and future use of biological specimens including genetic testing of blood samples and external shipment of specimens will also be sought from participants. However, in case of death of the mother, re-consenting will be sought from either the father or another family member who assume legal responsibility for the care and custody of the child. In case of a child death, the mother automatically ceases to continue participating in the study.

Sub-studies will require separate consent forms should they entail collection of additional data from study participants.

\section{Consent for publication}

Not applicable.

\section{Competing interests}

Authors have no competing interests.

\section{Author details}

${ }^{1}$ Department of Immunology, University of Zimbabwe College of Health Sciences (UZ-CHS), P.O. Box A178 Avondale, Harare, Zimbabwe. ${ }^{2}$ Department 
of Paediatrics and Child Health, UZ-CHS, Harare, Zimbabwe. ${ }^{3}$ UZ-CHS Research Support Centre, UZ-CHS, Harare, Zimbabwe. ${ }^{4}$ Department of Chemical Pathology, UZ-CHS, Harare, Zimbabwe. ${ }^{5}$ Department of Obstetrics and Gynaecology, UZ-CHS, Harare, Zimbabwe. ${ }^{6} \mathrm{Clinic}$ for Visceral Surgery and Medicine, Inselspital Bern and Bern University, Bern, Switzerland.

${ }^{7}$ Department of Community Medicine, UZ-CHS, Harare, Zimbabwe.

${ }^{8}$ Department of Medical Laboratory Sciences, UZ-CHS, Harare, Zimbabwe.

Received: 17 February 2020 Accepted: 21 September 2020

Published online: 02 October 2020

\section{References}

1. Slogrove AL, Schomaker M, Davies MA, Williams P, Balkan S, Ben-Farhat J, et al. The epidemiology of adolescents living with perinatally acquired HIV a cross-region global cohort analysis. PLoS Med. 2018 Mar;15(3):e1002514.

2. UNAIDS. UNAIDS DATA 2018. 2018.

3. Sokoya T, Steel HC, Nieuwoudt M, Rossouw TM. HIV as a cause of immune activation and Immunosenescence. Mediat Inflamm. 2017;2017:6825493.

4. Clerici M, Butto S, Lukwiya M, Saresella M, Declich S, Trabattoni D, et al. Immune activation in africa is environmentally-driven and is associated with upregulation of CCR5. Italian-Ugandan AIDS Project AIDS. 2000;14(14):208392.

5. De M. X. Perinatal mortality audit in a Zimbabwean district. Paediatr Perinat Epidemiol. 1989;3(3):284-93.

6. Hestvik E, Tylleskar T, Ndeezi G, Grahnquist L, Olafsdottir E, Tumwine JK, et al. Prevalence of helicobacter pylori in HIV-infected. HAART-naive Ugandan children: a hospital-based survey J Int AIDS Soc. 2011;14:34..

7. Harare N. Zimbabwe declares state of emergency in cholera outbreak. Newsday Harare Zimbabwe. 2018;13.

8. Mofenson LM, Laughon BE. Human immunodeficiency virus, mycobacterium tuberculosis, and pregnancy: a deadly combination. Clin Infect Dis. 2007 Jul 15;45(2):250-3.

9. Madzime S, Adem M, Mahomed K, Woelk GB, Mudzamiri S, Williams MA. Hepatitis B virus infection among pregnant women delivering at Harare maternity hospital, Harare Zimbabwe, 1996 to 1997. Cent Afr J Med. 1999; 45(8):195-8.

10. Mhandire D, Duri K, Kaba M, Mhandire K, Musarurwa C, Chimusa E, et al. Seroprevalence of Cytomegalovirus infection among HIV-infected and HIVuninfected pregnant women attending antenatal clinic in Harare. Zimbabwe Viral Immunol. 2019;32(7):289-95.

11. Smith LE, Mbuya MNN, Prendergast AJ, Turner PC, Ruboko S, Humphrey JH, et al. Determinants of recent aflatoxin exposure among pregnant women in rural Zimbabwe. Mol Nutr Food Res. 2017;61(9). https://doi.org/10.1002/ mnfr.201601049.

12. Owino VO. Challenges and opportunities to tackle the rising prevalence of diet-related non-communicable diseases in Africa. Proc Nutr Soc. 2019;8:1-7.

13. Samaras K, Gan SK, Peake PW, Carr A, Campbell LV. Proinflammatory markers, insulin sensitivity, and cardiometabolic risk factors in treated HIV infection. Obesity (Silver Spring). 2009;17(1):53-9.

14. Souza SJ, Luzia LA, Santos SS, Rondo PH. Lipid profile of HIV-infected patients in relation to antiretroviral therapy: a review. Rev Assoc Med Bras (1992). 2013;59(2):186-98.

15. Chikadaya H, Madziyire MG, Munjanja SP. Incidence of maternal near miss in the public health sector of Harare, Zimbabwe: a prospective descriptive study. BMC Pregnancy Childbirth. 2018;18(1):458.

16. Rose-Jacobs R, Black MM, Casey PH, Cook JT, Cutts DB, Chilton M, et al. Household food insecurity: associations with at-risk infant and toddler development. Pediatrics. 2008;121(1):65-72.

17. Andersen AM, Mortensen LH. Socioeconomic inequality in birth outcomes: what do the indicators tell us, and where do we find the data? CMAJ. 2006; 174(10):1429-30.

18. Spears D, Ghosh A, Cumming O. Open defecation and childhood stunting in India: an ecological analysis of new data from 112 districts. PLoS One. 2013;8(9):e73784.

19. Claudio CC, Patin RV, Palchetti CZ, Machado DM, Succi RC, Oliveira FL. Nutritional status and metabolic disorders in HIV-exposed uninfected prepubertal children. Nutrition. 2013;29(7-8):1020-3.

20. Papp E, Mohammadi H, Loutfy MR, Yudin MH, Murphy KE, Walmsley SL, et al. HIV protease inhibitor use during pregnancy is associated with decreased progesterone levels, suggesting a potential mechanism contributing to fetal growth restriction. J Infect Dis. 2015;211(1):10-8.
21. Estrella MM, Fine DM, Atta MG. Recent developments in HIV-related kidney disease. HIV Ther. 2010;4(5):589-603.

22. Liu H, Ma Y, Su Y, Smith MK, Liu Y, Jin Y, et al. Emerging trends of HIV drug resistance in Chinese HIV-infected patients receiving first-line highly active antiretroviral therapy: a systematic review and meta-analysis. Clin Infect Dis. 2014;59(10):1495-502.

23. Hofer CB, Keiser O, Zwahlen M, Lustosa CS, Frota AC, de Oliveira RH, et al. In utero exposure to antiretroviral drugs: effect on birth weight and growth among HIV-exposed uninfected children in Brazil. Pediatr Infect Dis J. 2016; 35(1):71-7.

24. Sofeu CL, Warszawski J, Ateba NF, Penda IC, Tetang NS, Guemkam G, et al. Low birth weight in perinatally HIV-exposed uninfected infants: observations in urban settings in Cameroon. PLoS One. 2014;9(4):e93554.

25. Ramokolo V, Lombard C, Fadnes LT, Doherty T, Jackson DJ, Goga AE, et al. HIV infection, viral load, low birth weight, and nevirapine are independent influences on growth velocity in HIV-exposed south African infants. J Nutr. 2014;144(1):42-8.

26. Shepherd BL, Ferrand R, Munyati S, Folkard S, Boyd K, Bandason T, et al. HLA correlates of long-term survival in vertically infected HIV-1-positive adolescents in Harare. Zimbabwe AIDS Res Hum Retroviruses. 2015;31(5):504-7.

27. Pitzen IC, Otten LA, Dresbach T, Boesecke C, Wasmuth JC, Mueller A, et al. Treatment of HIV in pregnancy - Progress over one decade. Z Geburtshilfe Neonatol. 2019;223(1):26-32

28. Zimbabwe ministry of health. Zimbabwe Ministry of Health and Child Care, 2012. Prevention of Mother to ChildTransmission of HIV 2012 Annu Rep 2012.

29. Rosala-Hallas A, Bartlett JW, Filteau S. Growth of HIV-exposed uninfected, compared with HIV-unexposed, Zambian children: a longitudinal analysis from infancy to school age. BMC Pediatr. 2017;17(1):80.

30. Sudfeld CR, Lei Q, Chinyanga Y, Tumbare E, Khan N, Dapaah-Siakwan F, et al. Linear growth faltering among HIV-exposed uninfected children. J Acquir Immune Defic Syndr. 2016;21. https://globalprojects.ucsf.edu.

31. Jumare J, Datong P, Osawe S, Okolo F, Mohammed S, Inyang B, et al. Compromised growth among HIV-exposed uninfected compared with unexposed children in Nigeria. Pediatr Infect Dis J. 2019;38(3):280-6.

32. Buonomo E, Germano P, Moramarco S, Rossi R, Malizia A, Scarcella P, et al. Early assessment of weight velocity can support frontline health workers in predicting malnutrition in HIV exposed infants: preliminary results from a dream cohort in Malawi. Trop Med Int Health. 2016;21:1013-8.

33. Afran L, Garcia KM, Nduati E, Urban BC, Heyderman RS, Rowland-Jones SL. HIV-exposed uninfected children: a growing population with a vulnerable immune system? Clin Exp Immunol. 2014;176(1):11-22.

34. Ades V, Mwesigwa J, Natureeba P, Clark TD, Plenty A, Charlebois E, et al. Neonatal mortality in HIV-exposed infants born to women receiving combination antiretroviral therapy in rural Uganda. J Trop Pediatr. 2013; 59(6):441-6.

35. Kattan M, Platzker A, Mellins RB, Schluchter MD, Chen XC, Peavy H, et al. Respiratory diseases in the first year of life in children born to HIV-1-infected women. Pediatr Pulmonol. 2001;31(4):267-76.

36. Pavlinac PB, John-Stewart GC, Naulikha JM, Onchiri FM, Denno DM, Odundo EA, et al. High-risk enteric pathogens associated with HIV infection and HIV exposure in Kenyan children with acute diarrhoea. AIDS. 2014;28(15):2287-96.

37. Evans C, Humphrey JH, Ntozini R, Prendergast AJ. HIV-exposed uninfected infants in Zimbabwe: insights into health outcomes in the pre-antiretroviral therapy era. Front Immunol. 2016;7:190.

38. McHenry MS, Balogun KA, McDonald BC, Vreeman RC, Whipple EC, Serghides L. In utero exposure to HIV and/or antiretroviral therapy: a systematic review of preclinical and clinical evidence of cognitive outcomes. J Int AIDS Soc. 2019 Apr;22(4):e25275.

39. Parker SE, Lijewski VA, Janulewicz PA, Collett BR, Speltz ML, Werler MM. Upper respiratory infection during pregnancy and neurodevelopmental outcomes among offspring. Neurotoxicol Teratol. 2016;57:54-9.

40. Muller WJ. Treatment of perinatal viral infections to improve neurologic outcomes. Pediatr Res. 2017:81(1-2):162-9.

41. Harrison GJ. Current controversies in diagnosis, management, and prevention of congenital cytomegalovirus: updates for the pediatric practitioner. Pediatr Ann. 2015;44(5):e115-25.

42. Shmueli E, Hadar E, Pardo J, Attias J, Amir J, Bilavsky E. Congenital Cytomegalovirus infection after a multiple birth pregnancy. Pediatr Infect Dis J. 2017;36(12):e298-302. 
43. Slyker JA, Richardson B, Chung MH, Atkinson C, Asbjornsdottir KH, Lehman DA, et al. Maternal highly active antiretroviral therapy reduces vertical Cytomegalovirus transmission but does not reduce breast Milk Cytomegalovirus levels. AIDS Res Hum Retrovir. 2017;33(4):332-8.

44. Garcia-Knight MA, Nduati E, Hassan AS, Nkumama I, Etyang TJ, Hajj NJ, et al. Cytomegalovirus viraemia is associated with poor growth and T-cell activation with an increased burden in HIV-exposed uninfected infants. AIDS. 2017;31(13):1809-18.

45. Yeh RF, Rezk NL, Kashuba AD, Dumond JB, Tappouni HL, Tien HC, et al. Genital tract, cord blood, and amniotic fluid exposures of seven antiretroviral drugs during and after pregnancy in human immunodeficiency virus type 1-infected women. Antimicrob Agents Chemother. 2009;53(6):2367-74

46. Briand N, Mandelbrot L, Le CJ, Tubiana R, Teglas JP, Faye A, et al. No relation between in-utero exposure to HAART and intrauterine growth retardation. AIDS. 2009;23(10):1235-43.

47. Li N, Sando MM, Spiegelman D, Hertzmark E, Liu E, Sando D, et al. Antiretroviral therapy in relation to birth outcomes among HIV-infected women: a cohort study. J Infect Dis. 2016;213(7):1057-64.

48. Bissinger R, Bouguerra G, Al Mamun BA, Waibel S, Abbes S, Lang F. Efavirenz induced suicidal death of human erythrocytes. Cell Physiol Biochem. 2015; 37(6):2496-507.

49. Caniglia EC, Patel K, Huo Y, Williams PL, Kapetanovic S, Rich KC, et al. Atazanavir exposure in utero and neurodevelopment in infants: a comparative safety study. AIDS. 2016;30(8):1267-78.

50. Cassidy AR, Williams PL, Leidner J, Mayondi G, Ajibola G, Makhema J, et al. In utero Efavirenz exposure and neurodevelopmental outcomes in HIV-exposed uninfected children in Botswana. Pediatr Infect Dis J. 2019;38(8):828-34.

51. Reliquet V, Brunet-Cartier C, Launay E, Raffi F. Developmental delay and behavioral disorders in 59 HIV-exposed uninfected infants. Transl Pediatr. 2017;6(1):27-31.

52. le Roux SM, Donald KA, Brittain K, Phillips TK, Zerbe A, Nguyen KK, et al. Neurodevelopment of breastfed HIV-exposed uninfected and HIVunexposed children in South Africa. AIDS. 2018;32(13):1781-91.

53. Grayhack C, Sheth A, Kirby O, Davis J, Sibliss K, Nkwihoreze H, et al. Evaluating outcomes of mother-infant pairs using dolutegravir for HIV treatment during pregnancy. AIDS. 2018;32(14):2017-21.

54. Zash R, Holmes L, Diseko M, Jacobson DL, Brummel S, Mayondi G, et al. Neural-tube defects and antiretroviral treatment regimens in Botswana. N Engl J Med. 2019;381(9):827-40.

55. Kakkar F, Lamarre V, Ducruet T, Boucher M, Valois S, Soudeyns H, et al. Impact of maternal HIV-1 viremia on lymphocyte subsets among HIVexposed uninfected infants: protective mechanism or immunodeficiency. BMC Infect Dis. 2014;14:236.

56. Dirajlal-Fargo S, Mussi-Pinhata MM, Weinberg A, Yu Q, Cohen R, Harris DR, et al. HIV-exposed-uninfected infants have increased inflammation and monocyte activation. AIDS. 2019;33(5):845-53.

57. Ono E. Nunes dos Santos AM, de Menezes Succi RC, Machado DM, de Angelis DS, Salomao R, et al. imbalance of naive and memory $T$ lymphocytes with sustained high cellular activation during the first year of life from uninfected children born to HIV-1-infected mothers on HAART. Braz J Med Biol Res. 2008:41(8):700-8.

58. Lohman-Payne B, Gabriel B, Park S, Wamalwa D, Maleche-Obimbo E, Farquhar C, et al. HIV-exposed uninfected infants: elevated cord blood interleukin 8 (IL-8) is significantly associated with maternal HIV infection and systemic IL-8 in a Kenyan cohort. Clin Transl Med. 2018;7(1):26.

59. Boulougoura A, Sereti I. HIV infection and immune activation: the role of coinfections. Curr Opin HIV AIDS. 2016;11(2):191-200.

60. Prendergast AJ, Szubert AJ, Berejena C, Pimundu G, Pala P, Shonhai A, et al. Baseline inflammatory biomarkers identify subgroups of HIV-infected African children with differing responses to antiretroviral therapy. J Infect Dis. 2016; 214(2):226-36.

61. Jones CE, Naidoo S. de BC, Esser M, Kampmann B, Hesseling AC. Maternal HIV infection and antibody responses against vaccine-preventable diseases in uninfected infants. JAMA. 2011;305(6):576-84.

62. Buchner A, Omar FE, Vermeulen J, Reynders DT. Investigating hepatitis B immunity in patients presenting to a paediatric haematology and oncology unit in South Africa. S Afr Med J. 2014;104(9):628-31.

63. Weinberg A, Lindsey J, Bosch R, Persaud D, Sato P, Ogwu A, et al. B and T cell phenotypic profiles of African HIV-infected and HIV-exposed uninfected infants: associations with antibody responses to the Pentavalent rotavirus vaccine. Front Immunol. 2017;8:2002.

64. Kidzeru EB, Hesseling AC, Passmore JA, Myer L, Gamieldien H, Tchakoute $C T$, et al. In-utero exposure to maternal HIV infection alters T-cell immune responses to vaccination in HIV-uninfected infants. AIDS. 20;28(10):1421-30.

65. Duri K, Gumbo FZ, Kristiansen KI, Kurewa NE, Mapingure MP, Rusakaniko S, et al. Antenatal HIV-1 RNA load and timing of mother to child transmission; a nested case-control study in a resource poor setting. Virol J. 2010;7:176

66. World Health Organization. ACQUIRED IMMUNODEFICIENCY SYNDROME (AIDS) : Proposed WHO criteria for interpreting results from Western blot assays for HIV-1, HIV-2, and HTLV-I/HTLV-II. Weekly Epidemiological Record. 1990; Report No.: 65(37).

67. Ministry of Health and Child Care Zimbabwe. Zimbabwe National Guidelines for HIV Testing and Counselling. 2014.

68. Gupta S, Kesarla R, Chotai N, Omri A. Development and validation of reversed-phase HPLC gradient method for the estimation of efavirenz in plasma. PLoS One. 2017;12(5):e0174777.

69. Mhandire K, Zijenah LS, Tshabalala M, Yindom LM, Mlambo T, Mhandire DZ, et al. KIR and HLA-C genetic polymorphisms influence plasma IP-10 concentration in antiretroviral therapy-naive HIV-infected adult Zimbabweans. OMICS. 2019;23(2):111-8.

70. Levey AS, Coresh J, Greene T, Stevens LA, Zhang YL, Hendriksen S, et al. Using standardized serum creatinine values in the modification of diet in renal disease study equation for estimating glomerular filtration rate. Ann Intern Med. 2006;145(4):247-54.

71. Keiser SD, Boyd KW, Rehberg JF, Elkins S, Owens MY, Sunesara I, et al. A high LDH to AST ratio helps to differentiate pregnancy-associated thrombotic thrombocytopenic purpura (TTP) from HELLP syndrome. J Matern Fetal Neonatal Med. 2012;25(7):1059-63.

72. WHO. Haemoglobin concentrations for the diagnosis of anaemia and assessment of severity. Vitamin and Mineral Nutrition Information System. Geneva: World Health Organization; 2011. WHO/NMH/NHD/MNM/11.1. 2011

73. World Health Organization. Use of glycated haemoglobin (HbA1c) in diagnosis of diabetes mellitus: abbreviated report of a WHO consultation. Geneva; 2011. Report No.: (No. WHO/NMH/CHP/CPM/11.1).

74. Armah G, Lewis KD, Cortese MM, Parashar UD, Ansah A, Gazley L, et al. A randomized, controlled trial of the impact of alternative dosing schedules on the immune response to human rotavirus vaccine in rural Ghanaian infants. J Infect Dis. 2016;213(11):1678-85.

75. Plotkin SA. Vaccines: correlates of vaccine-induced immunity. Clin Infect Dis. 2008:47(3):401-9.

76. Peltenburg NC, Schoeman JC, Hou J, Mora F, Harms AC, Lowe SH, et al. Persistent metabolic changes in HIV-infected patients during the first year of combination antiretroviral therapy. Sci Rep. 2018;8(1):16947.

77. Erwin EA, James HR, Gutekunst HM, Russo JM, Kelleher KJ, Platts-Mills TA. Serum IgE measurement and detection of food allergy in pediatric patients with eosinophilic esophagitis. Ann Allergy Asthma Immunol. 2010;104(6): 496-502.

78. Huss-Marp J, Gutermuth J, Schaffner I, Darsow U, Pfab F, Brockow K, et al. Comparison of molecular and extract-based allergy diagnostics with multiplex and singleplex analysis. Allergo J Int. 2015;24:46-53.

79. Kelishadi R, Hadi B, Iranpour R, Khosravi-Darani K, Mirmoghtadaee P, Farajian $\mathrm{S}$, et al. A study on lipid content and fatty acid of breast milk and its association with mother's diet composition. J Res Med Sci. 2012;17(9):824-7.

80. Henderson G, Yilmaz P, Kumar S, Forster RJ, Kelly WJ, Leahy SC, et al. Improved taxonomic assignment of rumen bacterial $16 \mathrm{~S}$ rRNA sequences using a revised SILVA taxonomic framework. PeerJ. 2019;7:e6496.

81. REUTERS/Philimon Bulawayo (Zimbabwe). 72 percent Zimbabweans living in poverty. The Zimbabwean Mail 2018

82. The business Connect Zimbabwe. Zim among the highest in Africa on Mobile Penetration . 2019. 27-5-2019. Ref Type: Online Source.

83. Kurewa EN, Gumbo FZ, Munjoma MW, Mapingure MP, Chirenje MZ, Rusakaniko S, et al. Effect of maternal HIV status on infant mortality: evidence from a 9-month follow-up of mothers and their infants in Zimbabwe. J Perinatol. 2010;30(2):88-92.

84. Faul Feelag \& B A. G*Power 3. A flexible statistical power analysis program for the social, behavioral, and biomedical sciences. 2007;39(2):175-91 Ref Type: Online Source. 
85. UNESCO. UNESCO, Literacy is nearly universal in Zimbabwe. 2019. 20-22019. Ref Type: Online Source.

86. Simms V, Dauya E, Dakshina S, Bandason T, Mchugh G, Munyati S, et al. Community burden of undiagnosed HIV infection among adolescents in Zimbabwe following primary healthcare-based provider-initiated HIV testing and counselling: a cross-sectional survey. PLoS Med. 2017;14(7):e1002360.

87. Roy NC. Use of mid-upper arm circumference for evaluation of nutritional status of children and for identification of high-risk groups for malnutrition in rural Bangladesh. J Health Popul Nutr. 2000;18(3):171-80.

88. Fakier A, Petro G, Fawcus S. Mid-upper arm circumference: a surrogate for body mass index in pregnant women. S Afr Med J. 2017;107(7):606-10.

89. WHO. The WHO growth charts. 2010. Ref Type: Online Source.

90. Frankenburg WK, Dodds J, Archer P, Shapiro H, Bresnick B. The Denver II: a major revision and restandardization of the Denver developmental screening test. Pediatrics. 1992;89(1):91-7.

91. Mullen EM. Mullen scales of early learning. MN:AGS: Circle Pines; 1995.

92. Howie SR. Blood sample volumes in child health research: review of safe limits. Bull World Health Organ. 2011;89(1):46-53.

93. Subramanian S, Huq S, Yatsunenko T, Haque R, Mahfuz M, Alam MA, et al. Persistent gut microbiota immaturity in malnourished Bangladeshi children. Nature. 2014;510(7505):417-21.

94. Mendez-Salazar EO, Ortiz-Lopez MG, Granados-Silvestre MLA, PalaciosGonzalez B, Menjivar M. Altered gut microbiota and compositional changes in Firmicutes and Proteobacteria in Mexican undernourished and obese children. Front Microbiol. 2018:9:2494.

95. Kau AL, Planer JD, Liu J, Rao S, Yatsunenko T, Trehan I, et al. Functional characterization of IgA-targeted bacterial taxa from undernourished Malawian children that produce diet-dependent enteropathy. Sci Transl Med. 2015;7(276):276ra24.

96. Uchimura Y, Fuhrer T, Li H, Lawson MA, Zimmermann M, Yilmaz B, et al. Antibodies set boundaries limiting microbial metabolite penetration and the resultant mammalian host response. Immunity. 2018;49(3):545-59.

97. Li H, Limenitakis JP, Fuhrer T, Geuking MB, Lawson MA, Wyss M, et al. The outer mucus layer hosts a distinct intestinal microbial niche. Nat Commun. 2015;6:8292.

98. Korpe PS, Petri WA Jr. Environmental enteropathy: critical implications of a poorly understood condition. Trends Mol Med. 2012;18(6):328-36.

99. Caradonna L, Amati L, Magrone T, Pellegrino NM, Jirillo E, Caccavo D. Enteric bacteria, lipopolysaccharides and related cytokines in inflammatory bowel disease: biological and clinical significance. J Endotoxin Res. 2000; 6(3):205-14.

100. Adriaanse MP, Tack GJ, Passos VL, Damoiseaux JG, Schreurs MW, van WK, et al. Serum I-FABP as marker for enterocyte damage in coeliac disease and its relation to villous atrophy and circulating autoantibodies. Aliment Pharmacol Ther. 2013;37(4):482-90.

101. Marchetti G, Tincati C, Silvestri G. Microbial translocation in the pathogenesis of HIV infection and AIDS. Clin Microbiol Rev. 2013;26(1):2-18.

102. Barclay GR, Scott BB, Wright IH, Rogers PN, Smith DG, Poxton IR. Changes in anti-endotoxin-lgG antibody and endotoxaemia in three cases of gramnegative septic shock. Circ Shock. 1989;29(2):93-106.

103. Serhan CN, Krishnamoorthy S, Recchiuti A, Chiang N. Novel antiinflammatory--pro-resolving mediators and their receptors. Curr Top Med Chem. 2011;11(6):629-47.

104. Agod Z, Fekete T, Budai MM, Varga A, Szabo A, Moon H, et al. Regulation of type I interferon responses by mitochondria-derived reactive oxygen species in plasmacytoid dendritic cells. Redox Biol. 2017;13:633-45.

105. Clerici M, Saresella M, Colombo F, Fossati S, Sala N, Bricalli D, et al. Tlymphocyte maturation abnormalities in uninfected newborns and children with vertical exposure to HIV. Blood. 2000;96(12):3866-71.

106. Clerici M, Sison AV, Berzofsky JA, Rakusan TA, Brandt CD, Ellaurie M, et al. Cellular immune factors associated with mother-to-infant transmission of HIV. AIDS. 1993;7(11):1427-33.

107. Smith C, Jalbert E, de A, V, Canniff J, Lenz LL, Mussi-Pinhata MM, et al. Altered Natural Killer Cell Function in HIV-Exposed Uninfected Infants. Front Immunol. 2017;8:470.

108. Katchar K, Soderstrom K, Wahlstrom J, Eklund A, Grunewald J. Characterisation of natural killer cells and CD56+ T-cells in sarcoidosis patients. Eur Respir J. 2005;26(1):77-85.

109. Houben RMGJ, Lalli M, Kranzer K, Menzies NA, Schumacher SG, Dowdy DW. What if they Don't have tuberculosis? The consequences and trade-offs involved in false-positive diagnoses of tuberculosis. Clin Infect Dis. 2019; 68(1):150-6.

110. Mok JH. Diagnosis and treatment of latent tuberculosis infection in healthcare workers. Tuberc Respir Dis (Seoul ). 2016;79(3):127-33.

111. Hucklebridge F, Hussain T, Evans P, Clow A. The diurnal patterns of the adrenal steroids cortisol and dehydroepiandrosterone (DHEA) in relation to awakening. Psychoneuroendocrinology. 2005;30(1):51-7.

112. Miller GE, Chen E, Zhou ES. If it goes up, must it come down? Chronic stress and the hypothalamic-pituitary-adrenocortical axis in humans. Psychol Bull. 2007;133(1):25-45

113. Dorn LD, Lucke JF, Loucks TL, Berga SL. Salivary cortisol reflects serum cortisol: analysis of circadian profiles. Ann Clin Biochem. 2007;44(Pt 3):281-4.

114. Ryan R, Booth S, Spathis A, Mollart S, Clow A. Use of salivary diurnal cortisol as an outcome measure in randomised controlled trials: a systematic review. Ann Behav Med. 2016:50(2):210-36.

115. Le DK, Bland R, Newell ML. Neurodevelopment in children born to HIVinfected mothers by infection and treatment status. Pediatrics. 2012;130(5): e1326-44.

116. Bouhet S, Le DE, Peres S, Fairbrother JM, Oswald IP. Mycotoxin fumonisin B1 selectively down-regulates the basal IL-8 expression in pig intestine: in vivo and in vitro studies. Food Chem Toxicol. 2006;44(10):1768-73.

117. Fan K, Xu J, Jiang K, Liu X, Meng J, Di Mavungu JD, et al. Determination of multiple mycotoxins in paired plasma and urine samples to assess human exposure in Nanjing, China. Environ Pollut. 2019;248:865-73.

118. Torres J, Leal-Herrera Y, Perez-Perez G, Gomez A, Camorlinga-Ponce M, Cedillo-Rivera $R$, et al. A community-based seroepidemiologic study of helicobacter pylori infection in Mexico. J Infect Dis. 1998;178(4):1089-94.

119. Kienesberger S, Perez-Perez Gl, Olivares AZ, Bardhan P, Sarker SA, Hasan KZ, et al. When is helicobacter pylori acquired in populations in developing countries? A birth-cohort study in Bangladeshi children. Gut Microbes. 2018; 9(3):252-63.

120. Lloyd-Price J, Mahurkar A, Rahnavard G, Crabtree J, Orvis J, Hall AB, et al. Erratum: strains, functions and dynamics in the expanded human microbiome project. Nature. 2017;551(7679):256.

121. Chandwani S, Beeler J, Li H, Audet S, Smith B, Moye J, et al. Safety and immunogenicity of early measles vaccination in children born to HIVinfected mothers in the United States: results of pediatric AIDS Clinical Trials Group (PACTG) protocol 225. J Infect Dis. 2011;204(Suppl 1):S179-89.

122. https://pt.knoema.com/atlas/sources/ZIMSTA. World Data Atlas Zimbabwe Health. 2019.

123. World Data Atlas Zimbabwe. Zimbabwe mortality rates. 2018.

124. CDC. Diagnostic Procedures - Stool Specimens. (2019, January 9). Retrieved 28 may 2019, from. 2019. Ref Type: Online Source. https://www.cdc.gov/ dpdx/diagnosticprocedures/stool/specimencoll.html.

\section{Publisher's Note}

Springer Nature remains neutral with regard to jurisdictional claims in published maps and institutional affiliations.

\section{Ready to submit your research? Choose BMC and benefit from:}

- fast, convenient online submission

- thorough peer review by experienced researchers in your field

- rapid publication on acceptance

- support for research data, including large and complex data types

- gold Open Access which fosters wider collaboration and increased citations

- maximum visibility for your research: over $100 \mathrm{M}$ website views per year

At $\mathrm{BMC}$, research is always in progress.

Learn more biomedcentral.com/submissions 